\title{
Observed intraseasonal and seasonal variability of the West India Coastal Current on the continental slope
}

\author{
P Amol, D Shankar*, V Fernando, A Mukherjee, $S$ G Aparna, R Fernandes, \\ G S Michael, S T Khalap, N P Satelkar, Y Agarvadekar, M G Gaonkar, \\ A P TARI, A Kankonkar and S P VERnEKar \\ CSIR-National Institute of Oceanography, Dona Paula, Goa 403 004, India. \\ ${ }^{*}$ Corresponding author.e-mail: shankar@nio.org
}

We present current data from acoustic Doppler current profilers (ADCPs) moored on the continental slope off the west coast of India. The data were collected at four locations (roughly at Kanyakumari, Kollam, Goa, and Mumbai) extending from $\sim 7^{\circ}$ to $\sim 20^{\circ} \mathrm{N}$ during 2008-2012. The observations show that a seasonal cycle, including an annual cycle, is present in the West India Coastal Current (WICC); this seasonal cycle, which strengthens northward, shows considerable interannual variability and is not as strongly correlated along the coast as in climatologies based on ship drifts or the altimeter. The alongshore decorrelation of the WICC is much stronger at intraseasonal periods, which are evident during the winter monsoon all along the coast. This intraseasonal variability is stronger in the south. A striking feature of the WICC is upward phase propagation, which implies an undercurrent whose depth becomes shallower as the season progresses. There are also instances when the phase propagates downward. At the two southern mooring locations off Kollam and Kanyakumari, the cross-shore current, which is usually associated with eddy-like circulations, is comparable to the alongshore current on occasions. A comparison with data from the OSCAR (Ocean Surface Currents Analyses Real-time) data product shows not only similarities, but also significant differences, particularly in the phase. One possible reason for this phase mismatch between the ADCP current at $48 \mathrm{~m}$ and the OSCAR current, which represents the current in the $0-30 \mathrm{~m}$ depth range, is the vertical phase propagation. Current products based on Ocean General Circulation Models like ECCO2 (Estimating the Circulation and Climate of the Ocean, Phase II) and GODAS (Global Ocean Data Assimilation System) show a weaker correlation with the ADCP current, and ECCO2 does capture some of the observed variability.

\section{Introduction}

The West India Coastal Current (WICC; Shankar and Shetye 1997) is the seasonally reversing eastern-boundary current of the Arabian Sea (figure 1a). Its seasonal cycle was mainly inferred from ship drifts (Anonymous 1944, 1952, 1960; Varadachari and Sharma 1967; Cutler and Swallow 1984; Shetye and Shenoi 1988; Rao et al. 1989;
Hastenrath and Greischar 1989; Shetye et al. 1994; Mariano et al. 1995), hydrography (Sastry and Myrland 1959; Banse 1959; Ramamirtham 1966; Düing 1970; Wyrtki 1971, 1973; Johannessen et al. 1987; Shetye et al. 1990, 1991a; Shetye and Gouveia 1998), drifters (Shenoi et al. 1999), and satellite altimetry (Bruce et al. 1994; Shankar and Shetye 1997; Shankar et al. 2002; Rao et al. 2009). The WICC, along with the current that flows along

Keywords. Eastern boundary current; Arabian Sea; Indian Ocean; acoustic Doppler current profiler; seasonal cycle; intraseasonal variability; time series. 
the eastcoast of India, the East India Coastal Current (EICC), actively participates in the exchange of water masses between the Arabian Sea and Bay of Bengal. The geographical location of India, which splits the North Indian Ocean (NIO) into two distinct, but connected, basins, the Arabian Sea and the Bay of Bengal, makes the WICC and EICC critical components of the circulation of the region. The exchange of heat and salt helps maintain the large-scale hydrological balance between the Arabian Sea, a concentration basin, and the Bay of Bengal, a dilution basin (Jensen 2001; Han et al. 2001) and plays a major role in the region's climate (see, for example, the reviews by Schott and McCreary 2001; Schott et al. 2009). The WICC also plays an important role in the biogeochemistry off the west coast of India (Naqvi et al. 2000, 2006; Dileepkumar 2006). The temporal and spatial distribution of biological productivity is strongly influenced by the seasonal reversal of currents (Lévy et al. 2007; McCreary et al. 2009). For example, the highest fish catch is mostly between October and March, and the fishery changes from south to north along the coast (Madhupratap et al. 2001; Raghukumar and Anil 2003). These links of the WICC to the regional climate and marine living resources imply that it is important to be able to describe its variability and understand what causes the observed variability.

In the rest of this introduction, we review our current state of knowledge of the WICC. We begin by presenting an overview of the climatological seasonal cycle, followed by a summary of the theoretical framework developed to explain these observations. Satellite altimeter data played an important role in the development of this framework and continue to be an important tool for mapping ocean currents; therefore, we devote a

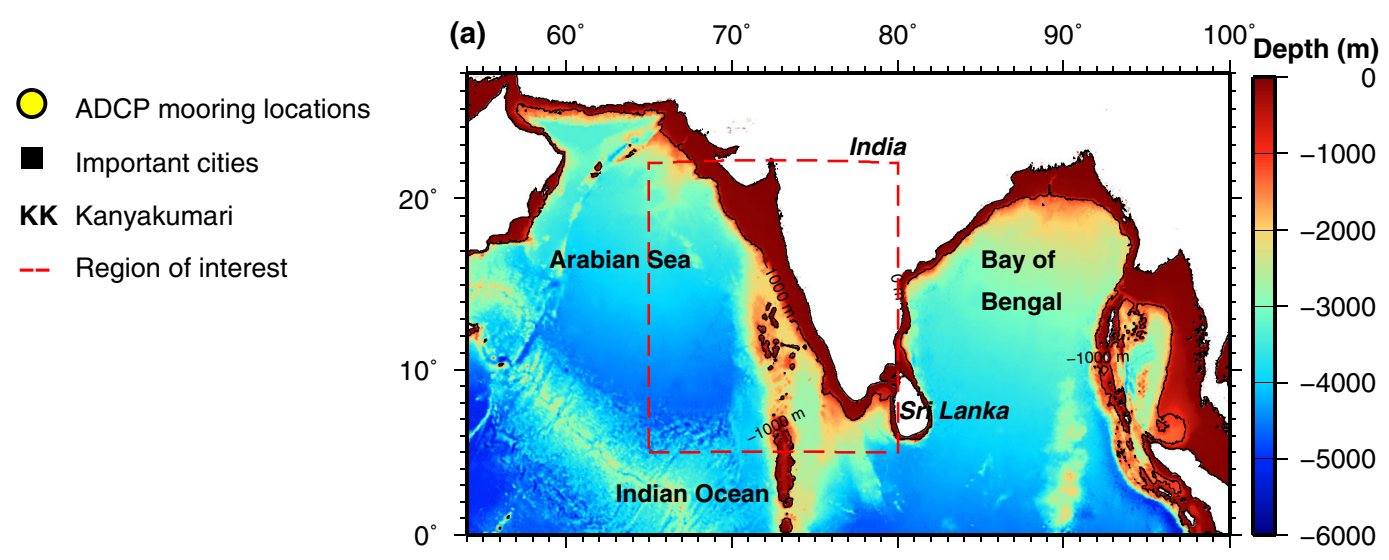

(b)

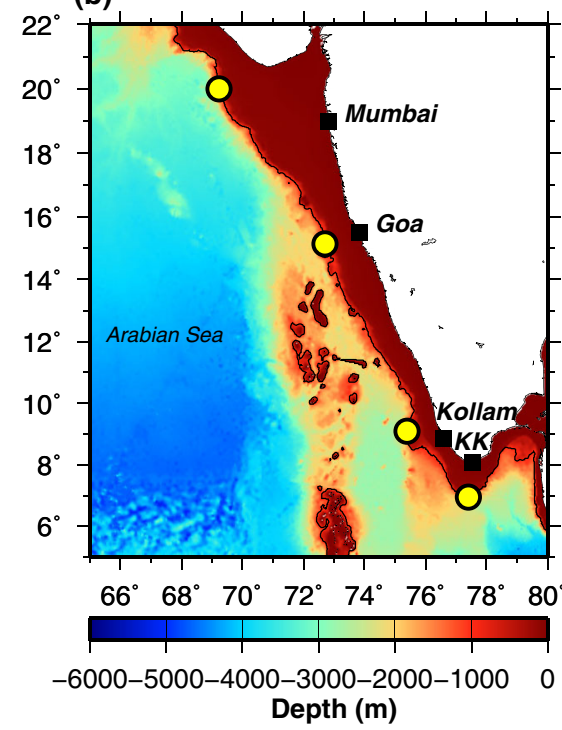

(c)

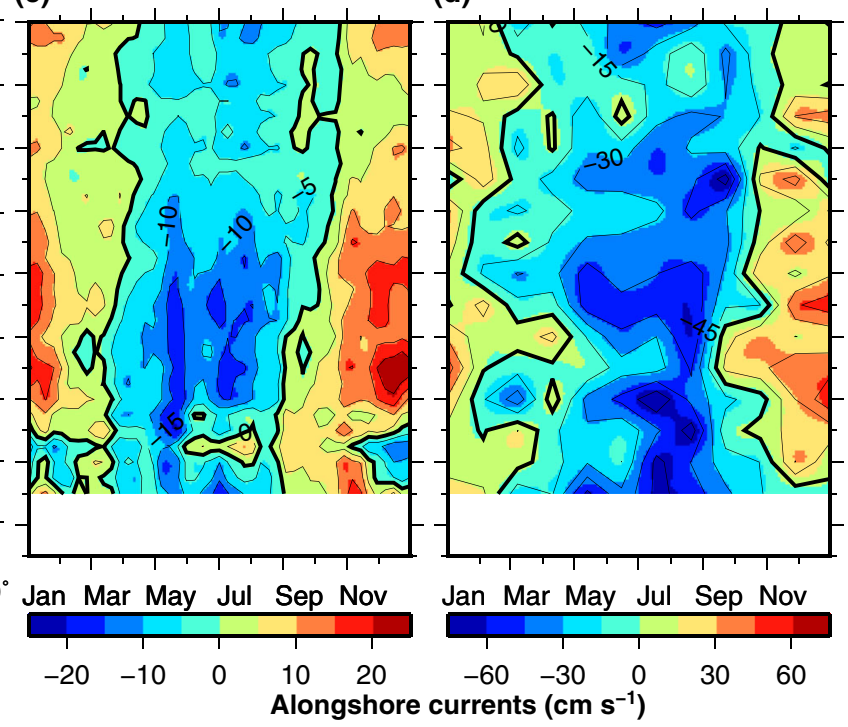

Figure 1. (a) Map of North Indian Ocean showing the region of interest. (b) ADCP mooring locations off the west coast of India at $1000 \mathrm{~m}$ water-column depth. The moorings are located at Kanyakumari $\left(7^{\circ} \mathrm{N}\right)$, Kollam $\left(9^{\circ} \mathrm{N}\right)$, Goa $\left(15^{\circ} \mathrm{N}\right)$ and Mumbai $\left(20^{\circ} \mathrm{N}\right)$ along the continental slope. The bathymetry is from Sindhu et al. (2007). (c) Weekly climatology of alongshore geostrophic currents estimated from the merged satellite altimetry data (AVISO 1996). (d) Monthly climatology of alongshore currents off the west coast of India from ship drifts (Mariano et al. 1995). Blue shade implies equatorward (westward) and red shade implies poleward (eastward) flow north (south) of $7^{\circ} \mathrm{N}$. 
subsection to the WICC as inferred from satellite altimetry. The review concludes by describing the results of direct measurements of the WICC using current meters or acoustic Doppler current profilers (ADCPs). The objectives of this paper are spelt out at the end of the introduction along with a brief summary of the major results.

\subsection{Climatological seasonal cycle}

Figure 1 shows the seasonal cycle of the WICC from monthly and weekly climatologies of ship-drift (Mariano et al. 1995) and altimeter (AVISO 1996) data, respectively. Drifter data are less useful for mapping the seasonal cycle owing to insufficient data in the regime of this boundary current (Shenoi et al. 1999). The WICC flows equatorward during the Indian summer monsoon (May-September) and poleward during the winter monsoon (November-February). There are some differences between the ship-drift and altimeter datasets: for example, the equatorward flow extends over more than half the year in shipdrifts and the equatorward (poleward) WICC is stronger in the ship-drifts (altimeter data). Nevertheless, both datasets show that the WICC is equatorward (upwelling-favourable) during the summer monsoon (May-September) and poleward (downwelling-favourable) during the winter monsoon (November-February). The monthly-mean alongshore winds are unidirectional, i.e., equatorward, along the west coast throughout the year (Shetye et al. 1985; Shetye and Shenoi 1988), and the poleward WICC during winter flows into the prevailing wind (Sharma 1968; Banse 1968). Both datasets also show that the upwelling-favourable equatorward flow sets in before the summer monsoon and the altimeter data confirm that it starts earlier in the south and progressively moves to the north, as had been suggested earlier on the basis of hydrographic data (Sharma 1968; Longhurst and Wooster 1990). The WICC, whether flowing poleward or equatorward, weakens to the north.

From the ship-drift and altimeter data, we get an estimate of only the surface current. Information on the subsurface circulation is available only from hydrographic data and from sparse direct current measurements. It was a set of cruises off the Indian west (Shetye et al. 1990, 1991a) and east (Shetye et al. 1991b, 1993, 1996) coasts that made possible a systematic investigation of the dynamics of the WICC and EICC by mapping these currents all along the Indian coast (see the reviews in Shetye and Gouveia 1998; Schott and McCreary 2001). The hydrographic observations show that the core of the WICC hugs the west-coast slope around the $1000 \mathrm{~m}$ isobath (Shetye et al. 1990). The equatorward geostrophic transport, estimated over the top $1000 \mathrm{~m}$, was found to increase during July-August from less than $0.5 \mathrm{~Sv}$ in the north to $\sim 4 \mathrm{~Sv}$ in the south. (Table 1 lists transport estimates available for the WICC.) The poleward WICC during winter, however, had a larger transport of $7 \mathrm{~Sv}$ and was wider at the south and better developed compared to the equatorward WICC during the summer monsoon (Shetye et al. 1991a). In the hydrography, these surface currents were about 100-250 $\mathrm{m}$ deep, below which there was a reversal in the tilting of isopycnals, suggesting an undercurrent (Sastry and Myrland 1959; Shetye et al. 1990, 1991a; Muraleedharan et al. 1995).

Note that these hydrographic data are restricted to a specific period during a given year, but the paucity of data often leads to them being considered representative of a quasi-climatological state.

\subsection{Theoretical studies}

Therefore, given the inability of the observations till the mid-1990s to describe anything beyond the climatological seasonal cycle of circulation, theoretical studies of the circulation of the NIO aimed at explaining the observed seasonal cycle of circulation in the basin. With respect to the WICC, Banse (1959) noted that the winds prevailing over the Arabian Sea were comparable to the winds over the other ocean basins during winter, but the circulation, with a poleward western-boundary current (off Somalia) was comparable to that in these basins during summer. Shetye and Shenoi (1988) noted that the WICC was comparable to other eastern-boundary, upwelling systems only during the summer monsoon. The poleward WICC during winter was attributed to a cross-shore salinity gradient that drove a geostrophic current into the wind (Johannessen et al. 1987) or an alongshore salinity, and therefore pressure, gradient that overwhelmed the equatorward wind, forcing a poleward WICC (Shetye et al. 1991a).

In order to explain the observed seasonal cycle of circulation off the Indian coast, model studies showed that it was necessary to invoke 'remote forcing' (i.e., forcing by winds remote to the region of interest, in this case, the east or west coasts of India), including the effect of winds blowing over the Equatorial Indian Ocean (EIO). Building on earlier work in the Pacific (see, for example, Wyrtki 1975; McCreary 1976; Hurlburt et al. 1976) and Atlantic (see, for example, O'Brien et al. 1978; Picaut 1983; McCreary et al. 1984) oceans, Potemra et al. (1991) and Yu et al. (1991) 
Table 1. Transport estimates available for the WICC.

\begin{tabular}{|c|c|c|c|}
\hline Reference & Method & Location and period & Transport estimates in $\mathrm{Sv}\left(10^{6} \mathrm{~m}^{3} \mathrm{~s}^{-1}\right)$ \\
\hline Düing (1970) & Hydrography & $10^{\circ} \mathrm{N}$, Aug-Sep, 1963 & $\begin{array}{l}\text { Poleward transport of } 0.8 \mathrm{~Sv} \text { near the coast } \\
\text { and } 14 \mathrm{~Sv} \text { equatorward off the coast }\end{array}$ \\
\hline Shetye et al. (1990) & Hydrography & $7^{\circ}-20^{\circ} \mathrm{N}$, Jun-Aug, 1987 & $\begin{array}{l}\text { Equatorward transport of } 0.5 \text { to } 4 \mathrm{~Sv} \text { from } \\
\text { north to south }\end{array}$ \\
\hline Shetye et al. (1991a) & Hydrography & $7^{\circ}-20^{\circ} \mathrm{N}$, Dec-Jan, $1987-1988$ & Poleward transport of $7 \mathrm{~Sv}$ \\
\hline Schott et al. (1994) & Moored ADCP & $\begin{array}{l}4^{\circ}-5^{\circ} \mathrm{N}, \text { Southern tip of Sri- } \\
\text { Lanka, Jan 1991-Feb } 1992\end{array}$ & $\begin{array}{l}\text { Transport of } 10-12 \mathrm{~Sv} \text { (westward) and } 8 \mathrm{~Sv} \\
\text { (eastward) for summer and winter monsoons, } \\
\text { respectively }\end{array}$ \\
\hline Stramma et al. (1996) & $\begin{array}{l}\text { Hydrography, } \\
\text { shipboard and } \\
\text { lowered ADCP }\end{array}$ & $8^{\circ} \mathrm{N}$, August 1993 & $\begin{array}{l}\text { A poleward transport of } 4.1 \mathrm{~Sv}(4.7 \mathrm{~Sv}) \text { was } \\
\text { observed near the coast and about } 4.7 \mathrm{~Sv} \\
(10.4 \mathrm{~Sv}) \text { equatorward away off the coast } \\
\text { from hydrography (ship ADCP) }\end{array}$ \\
\hline
\end{tabular}

used reduced-gravity models to show that remote forcing from the EIO had a significant impact on the circulation in the bay, including the EICC. A comprehensive study of the Indian-Ocean dynamics by McCreary et al. (1993) confirmed the importance of remote forcing for the seasonal cycle of the EICC and showed that remote forcing from the Bay of Bengal was important for the seasonal cycle of the WICC. A detailed study of the forcing mechanisms of the EICC by Shankar et al. (1996) and McCreary et al. (1996) quantified the role of both local (i.e., winds along the Indian east coast for the EICC) and remote forcing.

The numerical model of McCreary et al. (1993) did not include salinity, but was still able to simulate the poleward WICC during winter, implying that the alongshore pressure gradient was set up by coastal Kelvin waves driven from the east coast of India, rather than by the alongshore salinity gradient as envisaged by Shetye et al. (1991a). The role of Kelvin waves, forced along the east coast of India, was shown subsequently to be more important than local, west-coast winds in driving the seasonal cycle of the WICC (Shankar and Shetye 1997; Shankar et al. 2002). The larger contribution of the east-coast winds is due to geography, with the southwesterly and northeasterly winds during the summer and winter monsoons, respectively, blowing largely parallel to the east coast. In contrast, though the mean winds associated with the Findlater Jet (Findlater 1969) are stronger (Shenoi et al. 2002), the orientation of the west coast, largely normal to the prevailing winds, implies that the alongshore component off the west coast of India is weaker than the alongshore component off the east coast. Hence, the weaker monthly-mean winds off the Indian east coast can force coastal Kelvin waves with a larger amplitude than is seen off the west coast.

\subsection{Satellite altimetry}

The development of this theoretical framework, which invoked three long, baroclinic waves - Equatorial Rossby and Kelvin waves and coastal Kelivn waves - coincided with the advent of satellite altimetry, which provided a quasi-synoptic view of the seasonal cycle on the scale of the basin, making it possible to track the propagation of Rossby wave across the NIO. Using GEOSAT data, Bruce et al. (1994) identified a high in sea level in the southeastern Arabian Sea (SEAS) during winter; they showed that a similar, downwelling feature existed in the hydrographic data collected during the International Indian Ocean Expedition in the 1960s and called it the Laccadive (Lakshadweep) high. Shankar and Shetye (1997) showed that the Lakshadweep high formed during one phase of the seasonal cycle, with the Lakshadweep low replacing it during the summer monsoon in the SEAS. They showed that the high and low in the SEAS were intimately connected to the seasonal cycle of the WICC and that the wider WICC documented by Shetye et al. (1991a) off the southern part of the Indian west coast was due to the faster westward propagation of Rossby waves in the vicinity of the Equator.

All these results were, however, restricted to the seasonal cycle. A similar theoretical study of variability at shorter, intraseasonal periods off the Indian coast was precluded by the absence of direct current measurements. Only sea-surface temperature (SST) and sea-level anomaly (SLA) data were available to quantify the intraseasonal variability, with current measurements being restricted to the EIO (Sengupta et al. 2004; Masumoto et al. 2005; McPhaden et al. 2009) and, more recently the eastern Bay of Bengal (McPhaden et al. 2009). Durand et al. (2009) used a newly processed, along-track 
altimeter dataset (Birol et al. 2006; Durand et al. 2008) to show that the EICC, which was coherent along the coast at seasonal time scales, decorrelated along the coast at intraseasonal periods.

The altimeter data are available at an interval of 7-10 days and can therefore resolve periodicities of the order of 40-60 days and more. Mapping intraseasonal variability on shorter time scales is possible only through direct current measurements, which also offer the only means of mapping the vertical variations in the currents.

\subsection{Direct current measurements}

Owing largely to logistical reasons, primarily cost, only a few direct current measurements were made off the west coast of India prior to 2005 and they were mostly of short duration, ranging from a few hours to at most a fortnight. These observations, summarised in table 2, permitted the analysis of only high-frequency variability like internal waves, tides, and inertial currents. Nevertheless, the longer of these short-duration current records provided some backing for the seasonal cycle inferred from hydrography and ship drifts. For example, Shenoi and Antony (1991) noted the mean flow to be equatorward during March and May and poleward during November. These direct current measurements also showed an undercurrent (Hareeshkumar and Mohankumar 1996; Stramma et al. 1996). Stramma et al. (1996) noted that the poleward undercurrent in their ship-based ADCP data during August extended much closer to the surface compared to the undercurrent observed in the hydrographic data by Shetye et al. (1991a).

Shetye et al. (2008) used a one-month-long current-meter dataset on the west coast shelf to show that variability at periods less than 10 days during March-April 2003 was locally forced; at periods greater than 10 days, the current reversed, even though the wind remained unidirectional, implying the existence of a remotely forced current component. Shetye et al. (2008) used scatterometer data to show that the wind reversed only off Kollam in Kerala, suggesting that even at depths as shallow as $10-20 \mathrm{~m}$ on the continental shelf, remote forcing is important.

The dearth of direct current measurements has, however, limited theoretical studies of intraseasonal variability, which are important for enabling the development of a forecasting system for the Indian seas. Therefore, in order to quantify the variability in the circulation in the Indian Exclusive Economic Zone (EEZ) at periods ranging from a few days to a few weeks, an EEZ mooring programme was launched by the CSIR-NIO in 2006 . Moorings with ADCPs were deployed on the shelf and slope off the east and west coasts of India. The first description of the currents measured by these ADCPs along the slope was by Vialard et al. (2009), who noted that the upper-ocean current off Goa (see figure 1) was dominated by intraseasonal variability, unlike the altimeter SLAs, which showed a strong seasonal cycle. The seasonal cycle was practically absent in the $50 \mathrm{~m}$ ADCP current. This difference was attributed by Vialard et al. (2009) to the coastal trapping poleward of the critical latitude for Rossby waves (Moores 1968). At periods shorter than the critical period at the mooring latitude, i.e., at intraseasonal periods shorter than $\sim 90$ days, the sea-level signal was trapped at the boundary, leading to a strong alongshore intraseasonal coastal current in a quasigeostrophic equilibrium with the cross-shore sealevel gradient. In contrast, the seasonal sea-level signal radiated offshore as a Rossby wave, leading to a weak seasonal current and the dominance of the intraseasonal current in the ADCP record.

Amol et al. (2012) showed the existence of shelf waves in ADCP data collected during MarchSeptember 2008 from the shelf and slope over a $\sim 500 \mathrm{~km}$ distance off the central west coast of India, providing observational evidence for remote forcing along the Indian west coast. The data showed propagation of waves at periods as short as 4 days on several occasions, suggesting that the 10-day cutoff used by Shetye et al. (2008) to separate local and remote forcing worked owing to the absence of 4-day-period waves during MarchApril 2003. The data showed coherent variability along the coast on the shelf, but the intraseasonal WICC decorrelated rapidly on the slope. Even though the inter-mooring spacing was of the order of $200-250 \mathrm{~km}$, the correlation between the adjacent mooring pairs was weak on the slope. Amol et al. (2012) speculated that this decorrelation could be due to the downward propagation of energy along the west-coast slope, as had been conjectured earlier for intraseasonal periods by Nethery and Shankar (2007). At seasonal periods, the Kelvin wave propagates almost horizontally owing to the long wavelength, but it bends down in the form of a beam at intraseasonal periods. Such downward propagation of energy, associated with upward propagation of phase, led to an undercurrent developing in these ADCP data.

\subsection{Objective}

The objective of this paper is to document quantitatively the seasonal and intraseasonal variability of the WICC on the continental slope using long-term, time-series data from ADCPs deployed on four moorings during 2008-2012. Simultaneous 


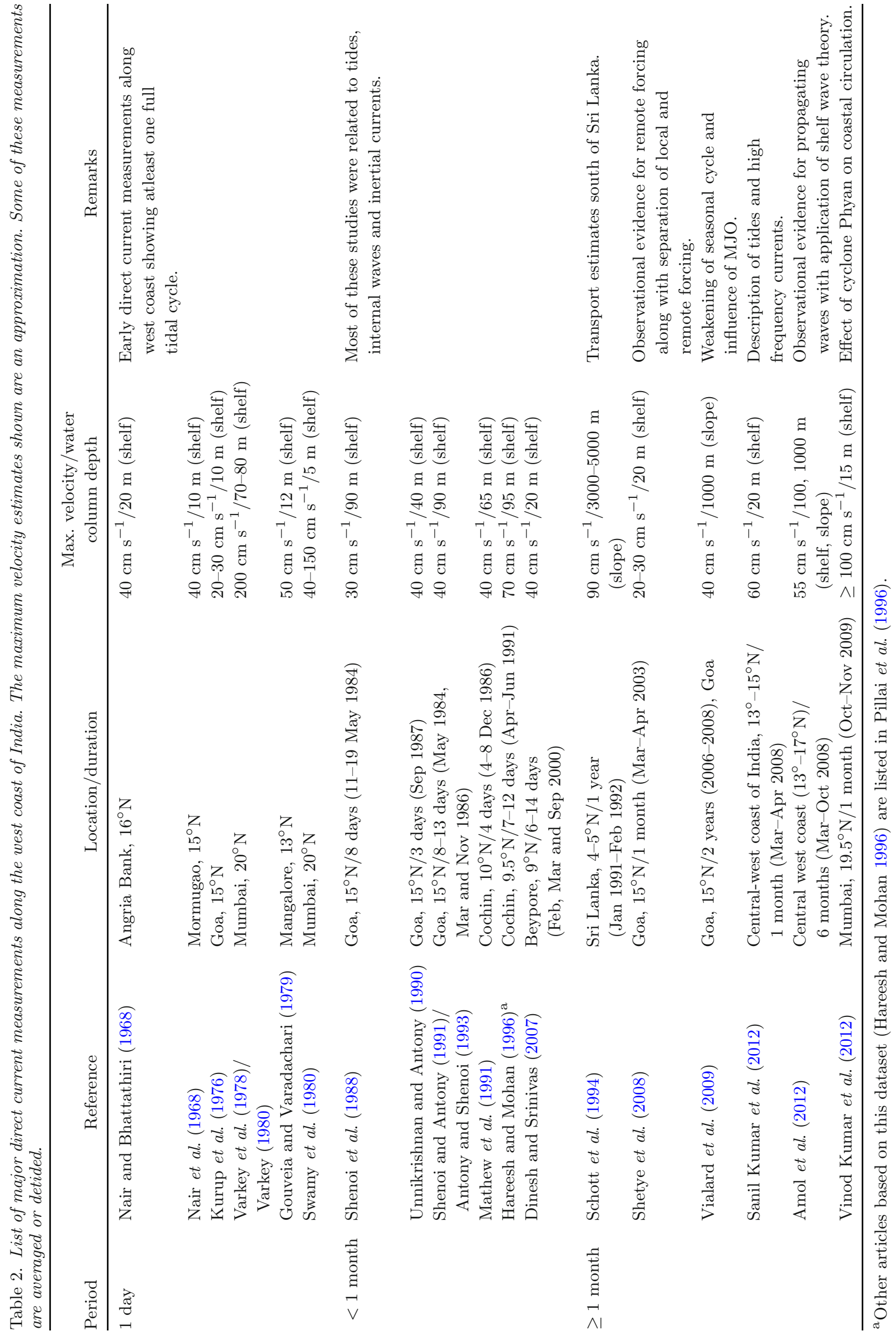


current data over the top $\sim 50-350 \mathrm{~m}$ of the water column from the southern tip of India to $\sim 20^{\circ} \mathrm{N}$ allows us to present the first description of the variability of the WICC at periods ranging from a few days to the annual cycle. We show the following features of the WICC. First, there does exist a seasonal cycle of the WICC and this seasonal cycle exhibits considerable interannual variability, with the strength of the annual cycle increasing poleward. Second, upward phase propagation, implying downward propagation of energy, is prominent for the annual cycle, leading to a shallowing of the undercurrent as the season progresses. Third, the seasonal WICC is weakly correlated along the coast, but the intraseasonal WICC is decorrelated. Fourth, the intraseasonal variability is stronger compared to the seasonal, and this intraseasonal variability occurs primarily during the winter monsoon. Fifth, the cross-shore current is not negligible at the two southern moorings off Kanyakumari and Kollam (in Kerala). The long dataset also allows us to compare the direct current measurements with popularly available ocean current data products.

The rest of the paper is organized as follows: the datasets used are described in section 2 and the alongshore and cross-shore currents are described in sections 3 and 4 , respectively. In section 5, we compare the ADCP data with current-data products that are popularly used for basin-scale studies. Section 6 concludes the paper. We note here that the scope of this paper is limited to presenting a quantitative analysis of the observed currents. We refrain from presenting a detailed cause-effect analysis because, as we show in section 5 , several of the observed features are not simulated by the models. Therefore, a discussion of the causes of the observed features is deferred to section 6 ; sections 3 and 4 primarily present the observations.

\section{Data}

\section{$2.1 A D C P$}

We use data from four ADCPs deployed on moorings on the continental slope, approximately along the $\sim 1100 \mathrm{~m}$ isobath, off the west coast of India (figure 1a). The moorings, located at approximately $7^{\circ} \mathrm{N}$ (Kanyakumari), $9^{\circ} \mathrm{N}$ (Kollam), $15^{\circ} \mathrm{N}$ (Goa), and $20^{\circ} \mathrm{N}$ (Mumbai) (figure $1 \mathrm{~b}$ ), were deployed during 2008-2012 (but the length of the data record is not the same for all moorings) with a sampling interval of one hour and a bin size of $8 \mathrm{~m}$. The mooring details are given in table 3 . The bin closest to the surface and common to all the measurements is centred at $48 \mathrm{~m}$. The accuracy of velocity measurements was better than $1.8 \mathrm{~cm} \mathrm{~s}^{-1}$. Following Amol et al. (2012), the gaps in the ADCP data were filled before analysis using the method of Kutsuwada and McPhaden (2002). The currents were detided using the Tidal Analysis Software Kit (TASK) (Bell et al. 1998) and all tidal constituents with a period of a day or less were removed. The detided currents were rotated by minimizing the cross-shore component below 100-150 m using a least-squares approach; above this depth, the crossshore component was often strong and could not be used to decompose the velocity field. (Note that 'cross-shore' in this case of slope currents is with reference to the shelf break, i.e., the $200 \mathrm{~m}$ isobath.)

\subsection{Data products}

'Data products' based on either satellite measurements or model simulations with data assimilation are commonly used as a measure of the observed circulation. In order to validate them, we compare the current estimates from three such popular data products with the ADCP measurements.

\subsubsection{OSCAR}

Ocean Surface Currents Analyses Real-time (OSCAR) (Bonjean and Lagerloef 2002) is an ocean-surface-current data product in which the velocities are derived from satellite measurements. SLA from altimeters, wind speed and direction from scatterometers, and SST are used in this diagnostic model to combine the geostrophic, EkmanStommel, and thermal-wind relations. The result is a current-vector field, representing the average current over the top $30 \mathrm{~m}$, on a $0.33^{\circ}$ grid every 5 days. OSCAR is a popular data product and has been used for several studies in the NIO (Ratman et al. 2009; Chacko et al. 2012; Sreenivas et al. 2012b, 2012a). We compare OSCAR currents with the ADCP measurements in section 5.1.

\subsubsection{ECCO2 and GODAS}

Unlike OSCAR, which is based on satellite data, two other popular data products, ECCO2 (Estimating the Circulation and Climate of the Ocean, Phase II) (Stammer et al. 2002a, b; Menemenlis et al. 2005) and GODAS (Global Ocean Data Assimilation System) (Behringer et al. 1998; Behringer and Xue 2004; Behringer 2007), are based on Ocean General Circulation Models (OGCMs).

ECCO2 is a cubed-sphere-model output interpolated on a $0.25^{\circ}$ grid (available every 3 days). It has 50 vertical levels and thickness ranges from $10 \mathrm{~m}$ near the surface to approximately $450 \mathrm{~m}$ at a depth 
Table 3. Mooring details.

\begin{tabular}{|c|c|c|c|c|c|c|c|c|}
\hline $\begin{array}{l}\text { Mooring } \\
\text { location }\end{array}$ & Position & $\begin{array}{c}\text { ADCP } \\
\text { no. }\end{array}$ & Start date & End date & $\begin{array}{l}\text { Start/end } \\
\text { depth }(\mathrm{m})\end{array}$ & $\begin{array}{c}\text { Water } \\
\text { depth }(\mathrm{m})\end{array}$ & $\begin{array}{l}\text { Angle } \\
(\mathrm{deg})\end{array}$ & $\begin{array}{c}\text { Inertial } \\
\text { period (days) }\end{array}$ \\
\hline \multirow[t]{3}{*}{ Kanyakumari } & $06.95^{\circ} \mathrm{N}$ & KK1 & 27 Oct 2009 & 09 Nov 2010 & $43 / 323$ & 1005 & 90 & 4.1 \\
\hline & $77.40^{\circ} \mathrm{E}$ & KK2 & 16 Nov 2010 & 24 Oct 2011 & $40 / 310$ & 995 & & \\
\hline & & KK3 & 24 Oct 2011 & 13 Oct 2012 & $35 / 267$ & 994 & & \\
\hline \multirow[t]{3}{*}{ Kollam } & $09.10^{\circ} \mathrm{N}$ & $\mathrm{K} 1$ & 29 Oct 2009 & 11 Nov 2010 & $40 / 336$ & 1125 & 07 & 3.2 \\
\hline & $75.40^{\circ} \mathrm{E}$ & $\mathrm{K} 2$ & 11 Nov 2010 & 21 Oct 2011 & $44 / 348$ & 1130 & & \\
\hline & & K3 & 21 Oct 2011 & 12 Oct 2012 & $48 / 408$ & 1113 & & \\
\hline \multirow[t]{5}{*}{ Goa } & $15.15^{\circ} \mathrm{N}$ & G1 & 17 Oct 2008 & 04 Nov 2009 & $38 / 326$ & 1142 & 14 & 1.9 \\
\hline & $72.70^{\circ} \mathrm{E}$ & G2 & 04 Nov 2009 & 04 Nov 2010 & $40 / 336$ & 1085 & & \\
\hline & & G3 & 04 Nov 2010 & 13 Oct 2011 & $36 / 332$ & 1115 & & \\
\hline & & G4 & 28 Oct 2011 & 15 Dec 2011 & $18 / 114$ & 1016 & & \\
\hline & & G5 & 15 Dec 2011 & 23 Jun 2012 & $21 / 165$ & 1021 & & \\
\hline \multirow[t]{4}{*}{ Mumbai } & $20.00^{\circ} \mathrm{N}$ & M1 & 21 Oct 2008 & 02 Nov 2009 & $39 / 351$ & 1100 & 07 & 1.5 \\
\hline & $69.25^{\circ} \mathrm{E}$ & M2 & 02 Nov 2009 & 06 Nov 2010 & $41 / 328$ & 1112 & & \\
\hline & & M3 & 06 Nov 2010 & 15 Oct 2011 & $39 / 343$ & 1128 & & \\
\hline & & M4 & 15 Oct 2011 & 04 Oct 2012 & $42 / 338$ & 1134 & & \\
\hline
\end{tabular}

The ADCPs are upward looking with a bin size of $8 \mathrm{~m}$ and a sampling interval of 1 hour. All ADCPs, except G4 and G5, are $75 \mathrm{kHz}$. The G4 and G5 ADCPs are $150 \mathrm{kHz}$ and measure only the top 100-150 m. The alongshore component was determined by rotating the axes anticlockwise: the angle given in column 8 is measured anticlockwise from the north, i.e., the angle is zero if the coast is oriented south-north.

of $4150 \mathrm{~m}$. In situ temperature, salinity and mean velocity from surface drifters are assimilated using an adjoint method (Marshall et al. 1997). ECCO2 has been used for a large number of oceanographic and interdisciplinary studies, including some in the NIO (Rao et al. 2012; Sreenivas et al. 2012a). A list of publications and reports since 2005 is available at http://ecco2.org/manuscripts.

GODAS is a real-time ocean analysis and is a reanalysis product developed at the National Centers for Environmental Prediction (NCEP). The product has been used for a few studies in NIO (Rao et al. 2011, 2012; Chacko et al. 2012; Wu et al. 2012) and a version of this model is used in the Indian Ocean Forecast System (INDOFOS) (Ravichandran et al. 2013). The model is based on GFDL's (Geophysical Fluid Dynamics Laboratory) MOMv3 (Modular Ocean Model version 3) (Pacanowski and Griffies 1998) and the data are assimilated in a 3D-VAR scheme (Derber and Rosati 1989). The model has 40 vertical levels with $10 \mathrm{~m}$ bins in upper $200 \mathrm{~m}$ and the resolution is $1^{\circ} \times 1^{\circ}\left(1^{\circ} \times 0.33^{\circ}\right.$ near the equator $)$. GODAS is forced by the momentum, heat, and freshwater fluxes from the NCEP Atmospheric Reanalysis (version 2). The data are available at a 5-day interval.

\section{Alongshore currents}

In this paper, we restrict our attention to the subinertial currents, but we do present spectra for the complete, detided current field to permit comparison between the magnitudes of the inertial and subinertial components. Since the inertial period at the southernmost location is of the order of 4 days, a 5-day low-pass filter (fourth-order Butterworth) was used to retain only the subinertial currents. This 5-day filter does eliminate the 4-day periodicity noted by Amol et al. (2012), but we use it for consistency.

\subsection{Subinertial currents}

We begin by presenting the alongshore subinertial current field (figure 2). The sign convention used is that the downwelling-favourable current is positive; the positive current is therefore poleward at Kollam, Goa, and Mumbai, and is westward at Kanyakumari, where the shelf-break is roughly zonal. Therefore, at Kanyakumari, the ADCP current is a measure of the local monsoon current, whose seasonal cycle is such that it flows eastward during the summer monsoon (Summer Monsoon Current or SMC) and westward during the winter monsoon (Winter Monsoon Current or WMC) (Shankar et al. 2002). On occasions, however, we do use the term WICC when referring to the current at Kanyakumari, but this use is motivated merely by the need for brevity.

The subinertial currents (figure 2) show strong intraseasonal variability, with this variability being particularly striking at Kanyakumari. Equally striking is upward phase propagation on several occasions, particularly at Mumbai and Goa. Associated with the upward phase propagation are 


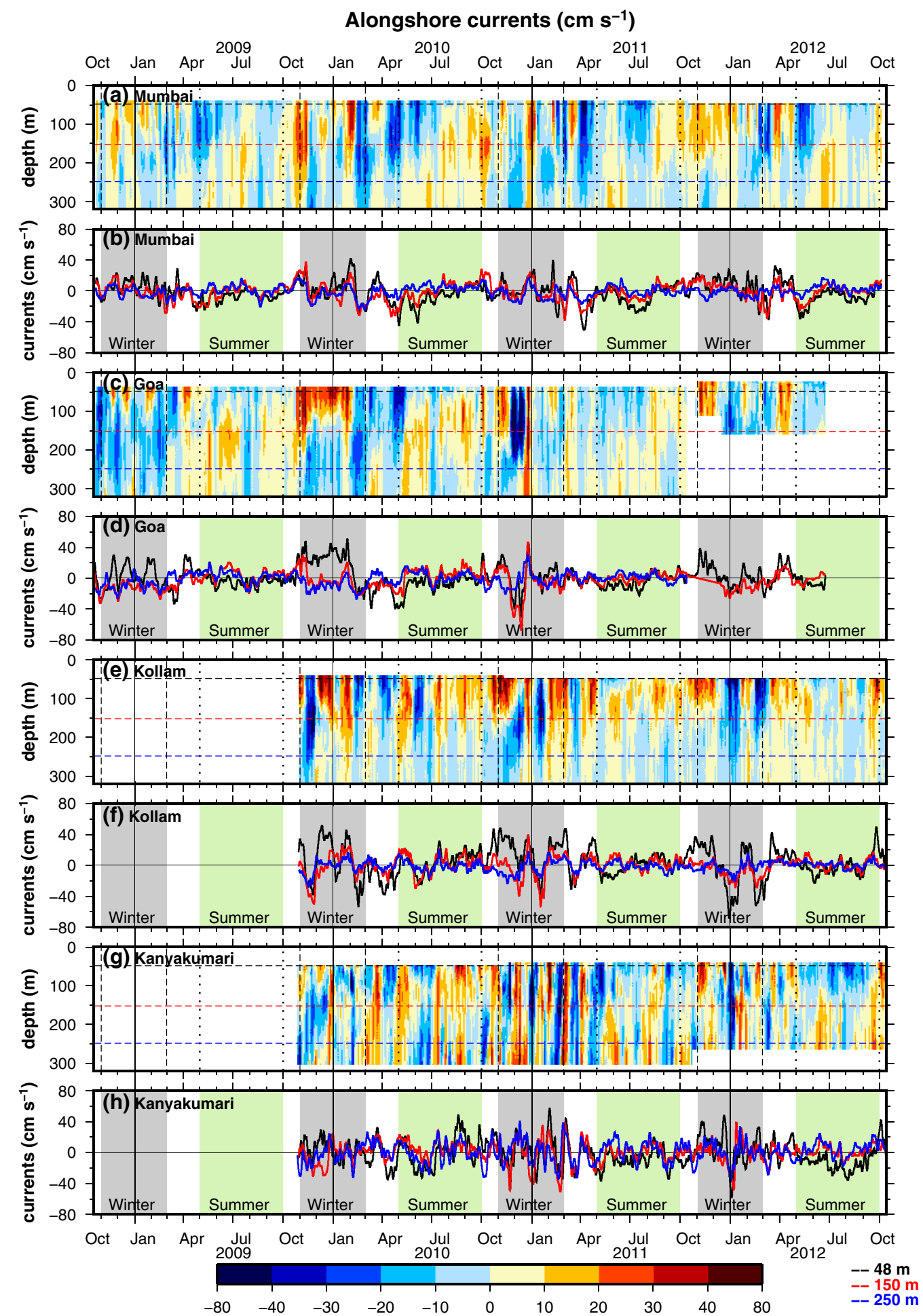

Figure 2. Panels (a), (c), (e), and (g) show the 5-day low-passed alongshore currents as a function of depth. Blue shade implies equatorward (eastward) flow and red shade poleward (westward) flow at Kollam, Goa, and Mumbai (Kanyakumari); this sign convention is used in all figures for the alongshore currents. The dotted and dashed vertical lines are drawn to delineate summer and winter monsoons, respectively. The dashed horizontal lines mark the $48 \mathrm{~m}$ (black), $150 \mathrm{~m}$ (red), and $250 \mathrm{~m}$ (blue) water depth. Panels (b), (c), (f), and (h) show corresponding line plots for currents at $48 \mathrm{~m}$ (black), $150 \mathrm{~m}$ (red), and $250 \mathrm{~m}$ (blue).

undercurrents. Except at Kanyakumari, the currents weaken with depth and often reverse below 150-200 m (see the line plots for Mumbai and Goa).
The currents at $48 \mathrm{~m}(150 \mathrm{~m})$ are weaker than $10 \mathrm{~cm} \mathrm{~s}^{-1}$ over $40 \%(60 \%)$ of the time (figure $\left.3 \mathrm{a}\right)$; the peak strength is $75 \mathrm{~cm} \mathrm{~s}^{-1}$ during the poleward 


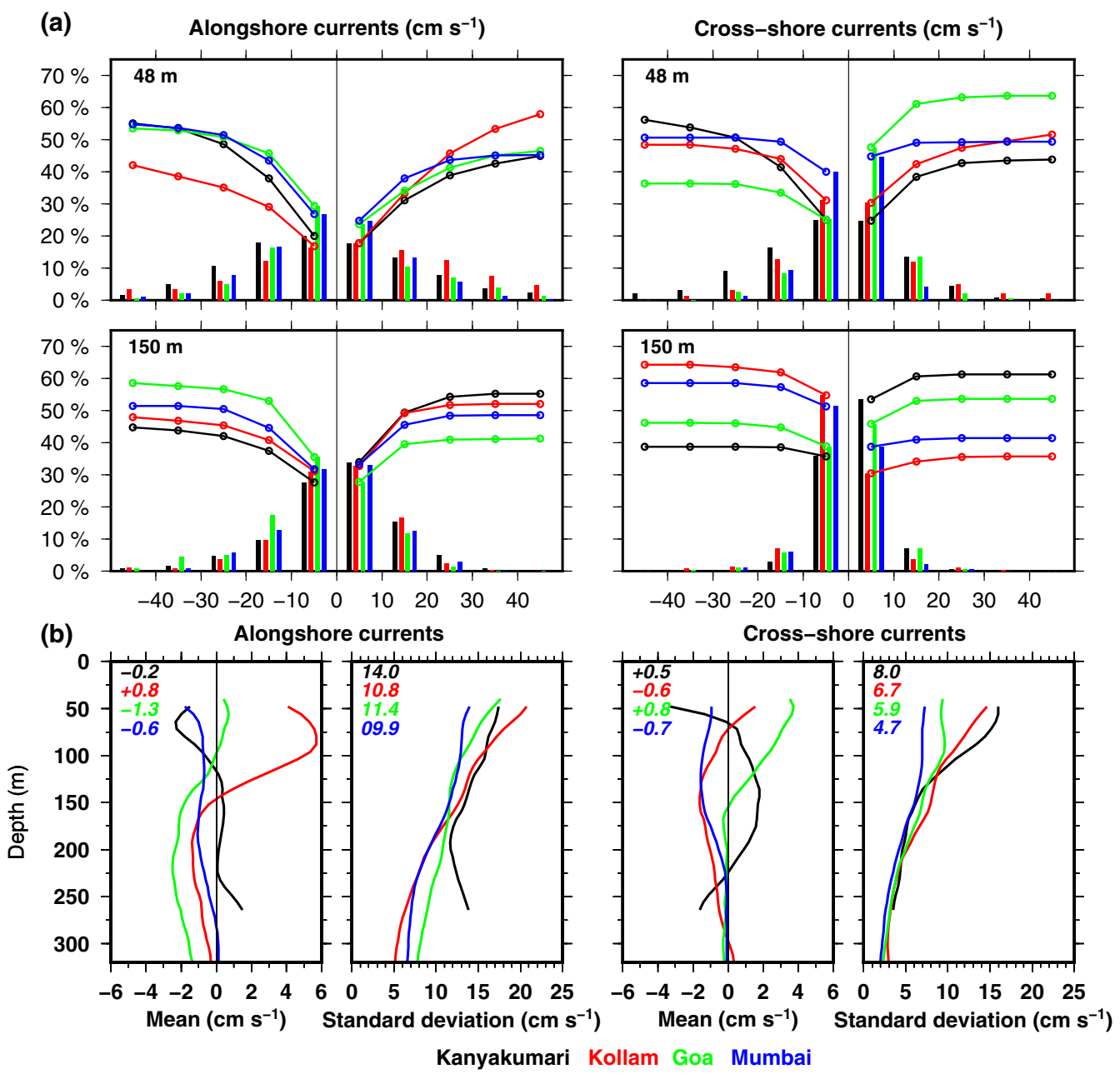

Figure 3. (a) Histogram and cumulative curve for both alongshore (left panels) and cross-shore currents (right panels) shown at $48 \mathrm{~m}$ (top panels) and $150 \mathrm{~m}$ (bottom panels). The histogram is calculated over $10 \mathrm{~cm} \mathrm{~s}^{-1}$ bin (interval) and currents greater than $|40| \mathrm{cm} \mathrm{s}^{-1}$ are grouped together in a single bin. The cumulative curve is shown separately for negative and positive values. The colour of the bars/lines depicts currents at different ADCP mooring locations. (b) Statistical mean and standard deviation as a function of depth for both alongshore (left panels) and cross-shore currents (right panels). The inset values in the top left corner show the total mean and standard deviation for each station.

burst at Goa in December 2009. At Kollam (Goa), the cumulative curve for the histogram shows a poleward (equatorward) WICC $58 \%$ (59\%) of the time. That the histograms are almost symmetric suggest a weak mean current, and this weak mean, of the order of $2 \mathrm{~cm} \mathrm{~s}^{-1}$ (comparable to the accuracy of the velocity measurements), is seen in figure 3(b). It is not merely the seasonal cycle of the WICC that leads to this near-zero mean flow: even the intraseasonal oscillations tend to cancel out over a year. An exception is seen at Kollam, where the mean current is poleward in the top $50 \mathrm{~m}$ owing to the current there being predominantly poleward from August 2010 onwards. At Kollam, there are far fewer equatorward bursts and they tend to occur during November-January. The near-zero mean current at Kanyakumari is in contrast to the observation of Schott et al. (1994), who noted a $17.5 \mathrm{~cm} \mathrm{~s}^{-1}$ westward mean current at $75 \mathrm{~m}$ during 1991-1992 at the southern tip of Sri Lanka. Except at Kollam, the annual mean calculated over each year does not exceed $4 \mathrm{~cm} \mathrm{~s}^{-1}$ and the near-surface annual mean flow at Kollam is always poleward every year (figure not shown). Schott et al. (1994) also noted a high standard deviation of $32.6 \mathrm{~cm} \mathrm{~s}^{-1}$, but the standard deviation is much weaker in the ADCP records presented here (figure 3b). The highest standard deviation is seen at $48 \mathrm{~m}$ at Kollam, but it decreases rapidly with depth. This decrease with depth is noted at Mumbai and Goa as well, but the variability is less at these locations. It is only at Kanyakumari that the standard deviation does not decrease much with depth, leading to the depth-averaged variability being highest there.

A spectrum (Fast Fourier Transform or FFT) of the alongshore current at $48 \mathrm{~m}$ shows strong peaks in the 30-90-day intraseasonal band 


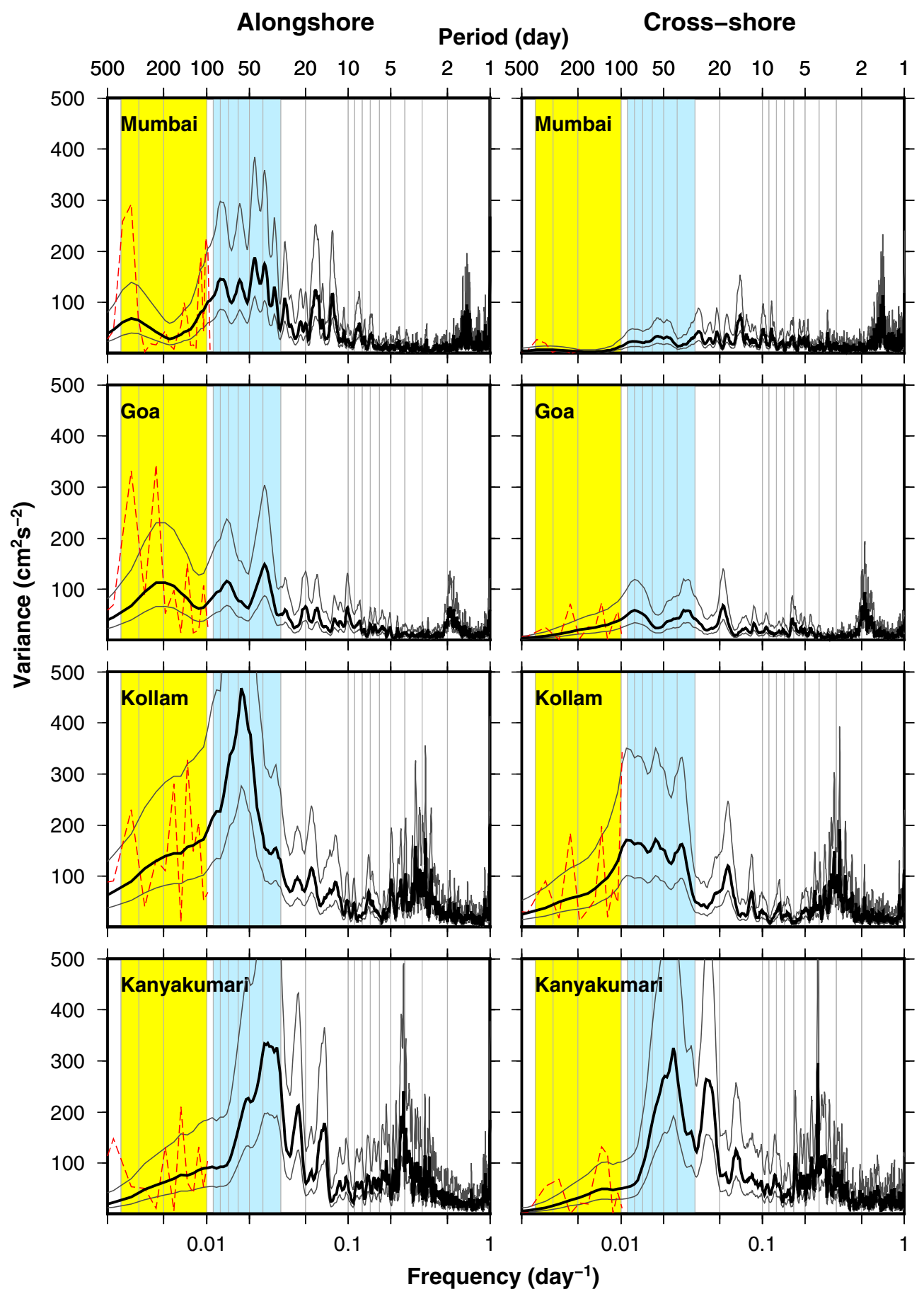

Figure 4. Variance preserving spectra shown for the raw alongshore currents (left panel) and cross-shore currents (right panel) at $48 \mathrm{~m}$. The spectra were smoothed using 7-point triangle filter after applying $75 \%$ Tukey window to the detrended and detided data. The gray lines show the $95 \%$ confidence interval for the smoothed spectra. The yellow (light blue) background shade highlights the seasonal cycle (30-90-day band). The dashed red lines show the raw spectra (not smoothed) for the seasonal band.

(figure 4). The intraseasonal peaks in the 30-90day band are stronger than the seasonal cycle at all locations, but the difference in the total energy is less at Goa compared to the other locations. The amplitude of intraseasonal band weakens poleward. The raw or unsmoothed spectrum of the alongshore current shows a strong peak at the annual cycle
( $\sim 365$ days), except at Kanyakumari, where the peak occurs instead at $\sim 450$ days. The FFT also shows comparable peaks in the 100-250-day band which contributes to the total energy in the seasonal band. With depth, the FFTs show peaks similar to those at the surface (figure not shown), but the spectral power decreases with depth, except for 
the seasonal band till $150 \mathrm{~m}$ at Mumbai and for the intraseasonal band at Kanyakumari and Goa.

The drawback of the FFT is that it picks the frequency over the entire record and does not account for the temporal variations in the strength of a given spectral peak. To describe this temporal variation of the spectral power at a given period, we use wavelet analysis, which shows a strong seasonal cycle and also suggests that its amplitude varies interannually (figure 5). (We use suggests in preference to shows because much of the wavelet power at the seasonal periods lies outside the cone of influence (COI), implying that the result does not pass the test of statistical significance. Padding of the data record with zeroes before computing the wavelet transform also weakens the wavelet power near the end of the data record. This distinction in inference is made throughout this paper, with the use of suggests implying a lack of statistical significance, primarily due to the short length of the data record.) For example, the seasonal cycle at Goa is strong during 2009-2010, but weakens thereafter, and the annual cycle at Kanyakumari, weak in the FFT (figure 4), is missing during 2011 in the wavelet power spectrum. Nevertheless, the weak annual cycle reported by Vialard et al. (2009) at Goa during 2006-2008, in contrast to the strong annual peak observed in the wavelet power in 2010 (figure 5), suggests that there is considerable interannual variability in the seasonal cycle of the WICC. The wavelets show that the intraseasonal peak (30-90 days), which is strongest at Kollam, occurs only during the winter monsoon (December-March) at all locations, but this peak extends into the summer monsoon on some occasions. The dominant frequencies vary with year and location, however, resulting in the multiple peaks in the FFT.

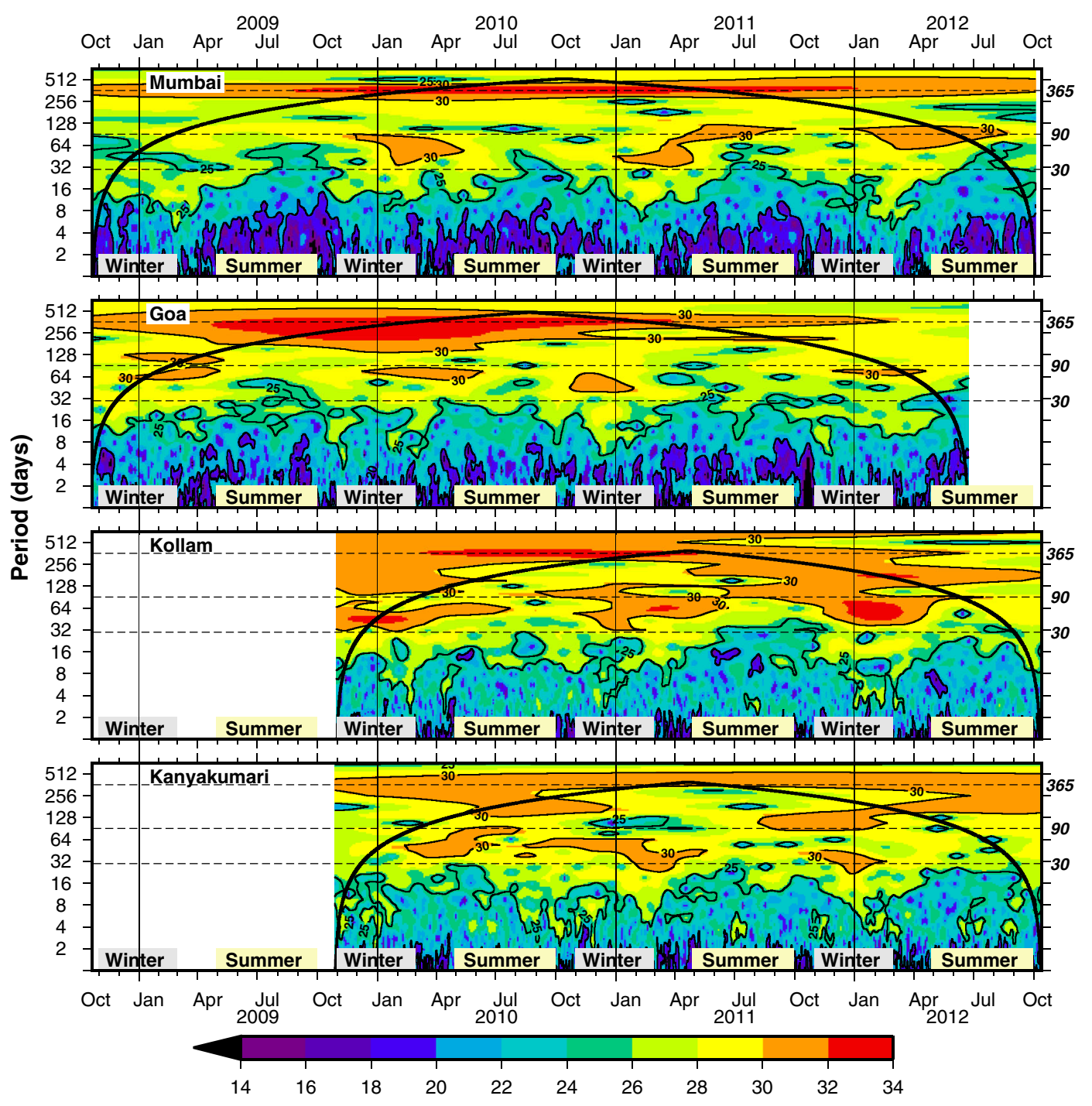

Figure 5. Morlet wavelet power spectra for alongshore currents at $48 \mathrm{~m}$. The thick black lines show the cone of influence (COI) for the wavelet power spectra. The wavelet power and the ordinate axis are plotted on a $\log _{2}$ scale. The horizontal dashed lines mark the 30-day, 90-day, and 365-day periods. 
Based on the spectral analysis (FFT and wavelets), we separate the subinertial current into seasonal (period 100-400 days) and intraseasonal (period 30-90 days) components.

\subsection{Seasonal cycle}

If we consider the seasonal cycle to be the variability that can be described by monthly data, then the periods that can be resolved are of the order of a few months. Prominent amongst the periodicities within this 100-400-day band are the annual cycle, the semi-annual cycle (period around 180 days), and a peak around 120 days (figures 4 and 5). Of these three periodicities, the annual and semiannual are the best documented in the literature (see section 1), with the former being forced by the seasonal reversal of winds and the latter by the asymmetry of the wind forcing (the winds during the summer monsoon are stronger than those during the winter monsoon) and from the equator, where resonance at the semi-annual period leads to stronger semi-annual variability compared to the annual cycle (Jensen 1993; Han et al. 1999; Schott and McCreary 2001).

Though the ship drifts and altimeter data (figure 1) suggest that the seasonal WICC is upwelling-favourable (downwelling-favourable) and flows equatorward (poleward) during the summer (winter) monsoon, the ADCP data show (figure 2) that this seasonal cycle is not as prominent as in even the weekly climatology based on altimetry. During the summer monsoon, the near-surface current at Goa and Mumbai does flow equatorward, but is weak (see the line plots in figure 2). At Kollam (Kanyakumari), the upwelling-favourable, equatorward (eastward) flow during the summer monsoon is punctuated by strong poleward (westward) bursts. At Kollam (Kanyakumari), the WICC (SMC) flows largely poleward (westward) during the summer monsoon of 2010 and weakly so in 2011; it is only during the 2012 summer monsoon that the WICC and SMC at these locations are in the same direction (equatorward/eastward) as in the climatology (Schott and McCreary 2001; Shankar et al. 2002). During the winter monsoon, the expected poleward flow is evident only at Goa in 2009 and at Mumbai in 2011. In other years at Goa and Mumbai and at Kollam in all years, the poleward flow is punctuated by equatorward bursts. Likewise, at Kanyakumari, the westward WMC is punctuated by eastward bursts, with the WMC matching the seasonal climatology only during the summer of 2010. To distinguish the annual and intra-annual components of the seasonal cycle, we filtered the data using band-pass filters over the period ranges $300-400$ days and 100-250 days, respectively.
Perhaps the most striking feature of the annual cycle (figure 6) is upward phase propagation at all locations. The filtered data also show subsurface current cores, i.e., strong currents below the surface layer. These cores are more prominent in the band-averaged (300-400 days) wavelet transform (figure not shown). With the exception of such cores, in general, the seasonal WICC weakens with depth at all locations. As with the wavelet analysis (figure 5), the filtered data suggest considerable interannual variability in the annual cycle. For example, at Goa, the strongest currents are observed during 2009-2010 in the top $100 \mathrm{~m}$, but this signal weakens by 2012 . The amplitude of the annual cycle also increases poleward with depth.

Unlike the annual cycle, which is strongest at Mumbai, the intra-annual component of the seasonal cycle, i.e., the $100-250$ day band, is weaker at Mumbai compared to Goa and Kollam (figure 7). It is also stronger during the winter monsoon compared to the summer monsoon and near the surface. Several instances of upward phase propagation are evident, but there are also several instances when phase propagates downward. Subsurface cores are also observed in this band, but, in general, the current in this band also weakens with depth.

To quantify the alongshore coherence, we use Wavelet Coherence Analysis (WCA), which identifies the region of strong local correlation between two time series for each frequency (or period) and also provides information on their phase relationship. The WCA suggests (note that much of the annual cycle lies outside the COI of the wavelet power spectrum) strong coherence between the WICC at Goa and Mumbai for the annual cycle (figure 8); the two stations are either in phase, or Goa leads Mumbai, as is expected because coastal Kelvin waves propagate poleward along the Indian west coast. The Kanyakumari-Kollam coherence is low; a possible cause is the weak annual cycle at Kanyakumari (figure 4). The short length of the data record common to Kollam and Goa restricts the WCA to periods shorter than 360 days. In the intra-annual band (100-250 days), the coherence is weaker and patchy between Goa and Mumbai, but is stronger between Kollam and Goa. The coherence between Kanyakumari and Kollam is stronger at the 110-day period compared to the annual cycle, but the latter leads the former.

\subsection{Intraseasonal variability}

We define the intraseasonal band to range from a few days to 90 days, but split it into two parts, a low-frequency part ranging from 30-90 days and a high-frequency part for periods shorter than 30 days. 


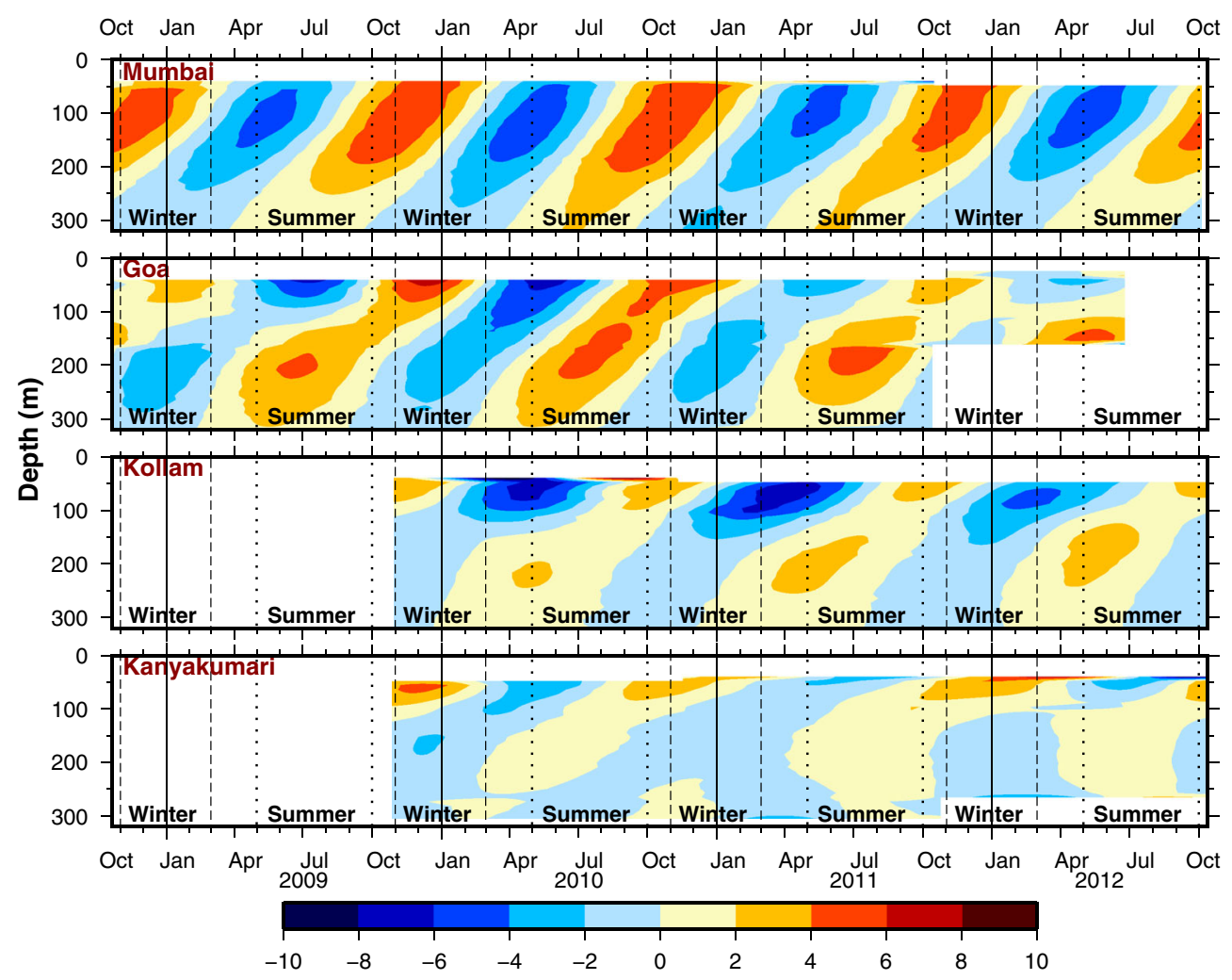

Figure 6. 300-400-day band-passed alongshore currents $\left(\mathrm{cm} \mathrm{s}^{-1}\right)$.

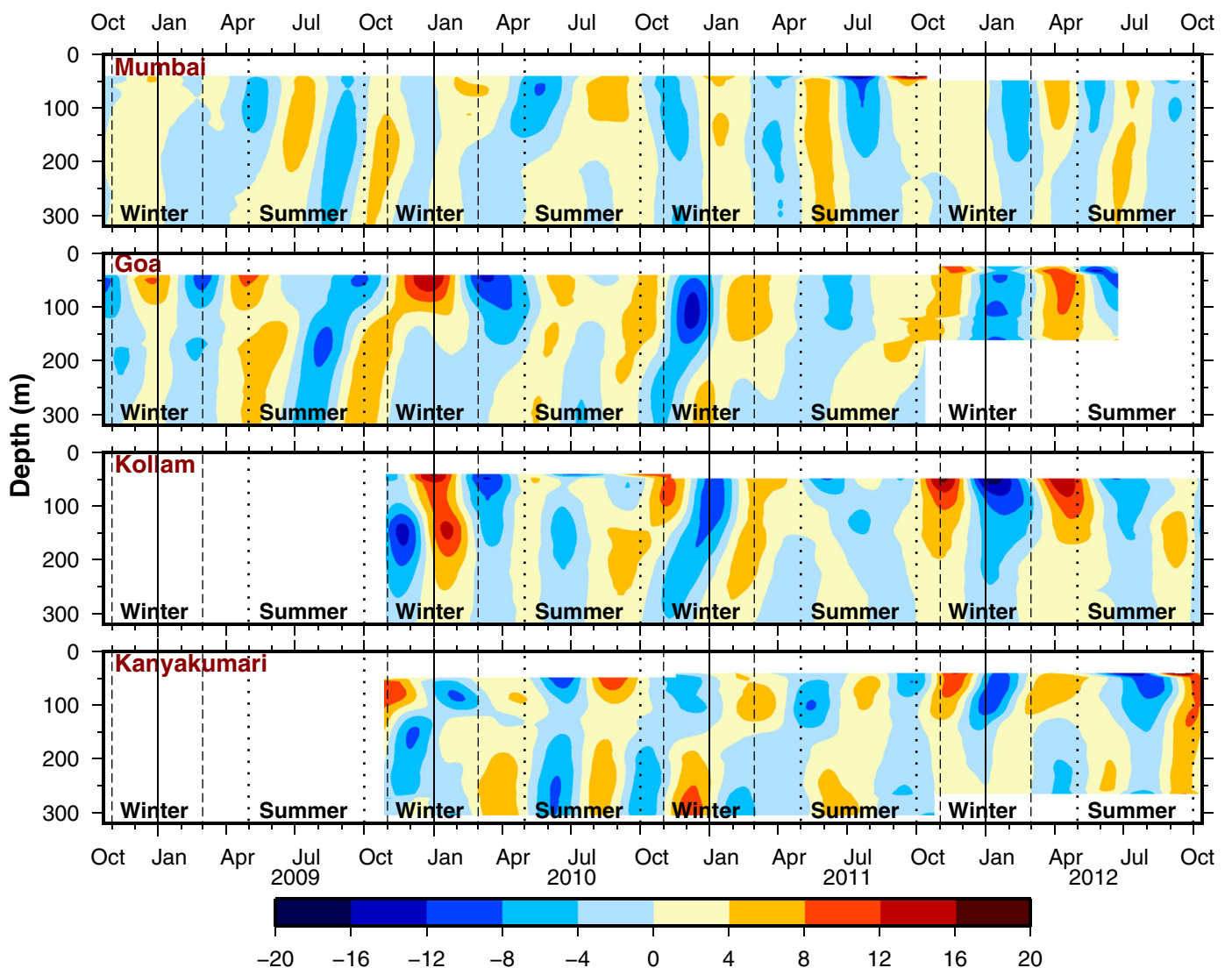

Figure 7. 100-250-day band-passed alongshore currents $\left(\mathrm{cm} \mathrm{s}^{-1}\right)$. 


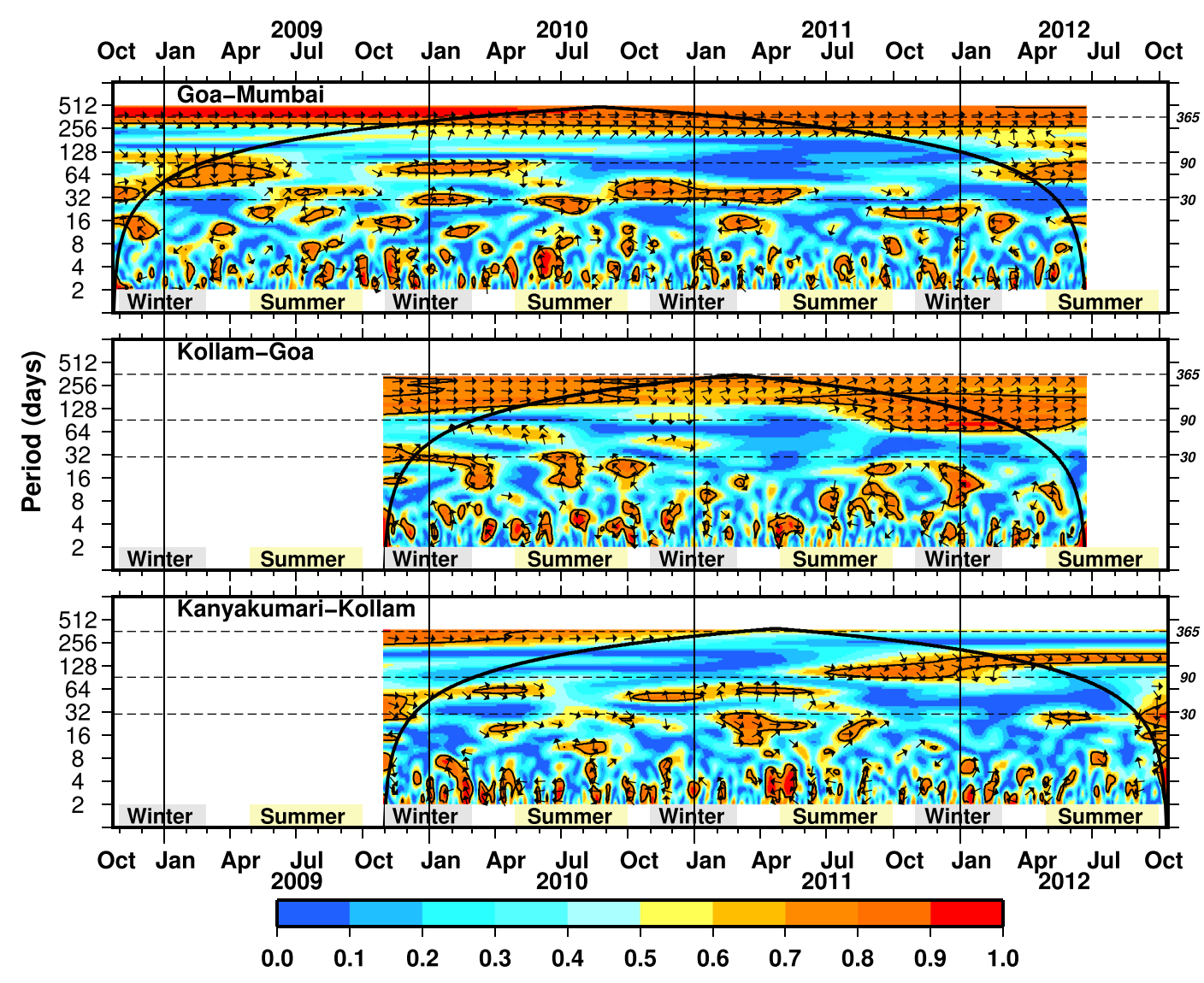

Figure 8. Wavelet coherence for the alongshore currents at $48 \mathrm{~m}$. The contour line shows $5 \%$ significance level against red noise and the thick black line shows the cone of influence (COI). The arrows show the relative phase relationship with in-phase (anti-phase) pointing right (left). The first station leads (lags) the second station in anticlockwise (clockwise) direction. The arrows are shown for only wavelet coherence of 0.5 or more. In order from top to bottom, the panels show the wavelet coherence for the pairs (a) Goa-Mumbai, (b) Kollam-Goa, and (c) Kanyakumari-Kollam. Note that the ordinate (period) is plotted on a $\log _{2}$ scale. The horizontal dashed lines mark the 30-day, 90-day and 365-day periods.

As with the intra-annual (100-250-day) component of the seasonal cycle, the peak in the 30 90-day intraseasonal band occurs during the winter monsoon at all locations, but, with the exception of Goa, this variability extends into April (figure 9). Variability in this low-frequency intraseasonal band is much weaker during the summer monsoon. The magnitude of this intraseasonal component, whether poleward (westward) or equatorward (eastward), varies with location, but is greater (a peak of $\sim 46 \mathrm{~cm} \mathrm{~s}^{-1}$ ) than that of the seasonal component. The strong peaks observed in the near-surface current extend to 150-200 m and strong subsurface cores are also observed in this band. Both upward and downward phase propagation are seen, but are not as prominent as in the other bands.

The data (figure 9) suggest a lack of coherence between the moorings in the 30-90-day band. The WCA shows that the WICC in this band is coherent only between Goa and Mumbai and, on occasions, between Kanyakumari and Kollam (figure 8).
In the beginning of 2009, however, the current at Goa lags that at Mumbai.

At intraseasonal periods shorter than 30 days, the inertial current (inertial periods are listed in table 3) is the most striking of the peaks. The magnitude of the inertial peak is comparable to the annual peak (figure 4), but as the inertial signal is monochromatic, the inertial peak has lower energy level compared to the seasonal band. Other prominent peaks in this high-frequency intraseasonal band are at 20-22, 15 , and 12 days. The $12-$ day period noted by Amol et al. (2012) along the central west coast of India during March-October 2008 is weak, but is observed at all locations; in this 3-year record, the wavelet power in this band (figure 5) is greater during winter at Mumbai, Kollam, and Kanyakumari, but comparable bursts occur during summer at Goa. The coherence, as may be expected, is as patchy as these bursts. At the lower period of 4 days also noted by Amol et al. (2012), who traced its propagation from south to north along the coast, the signal weakens 


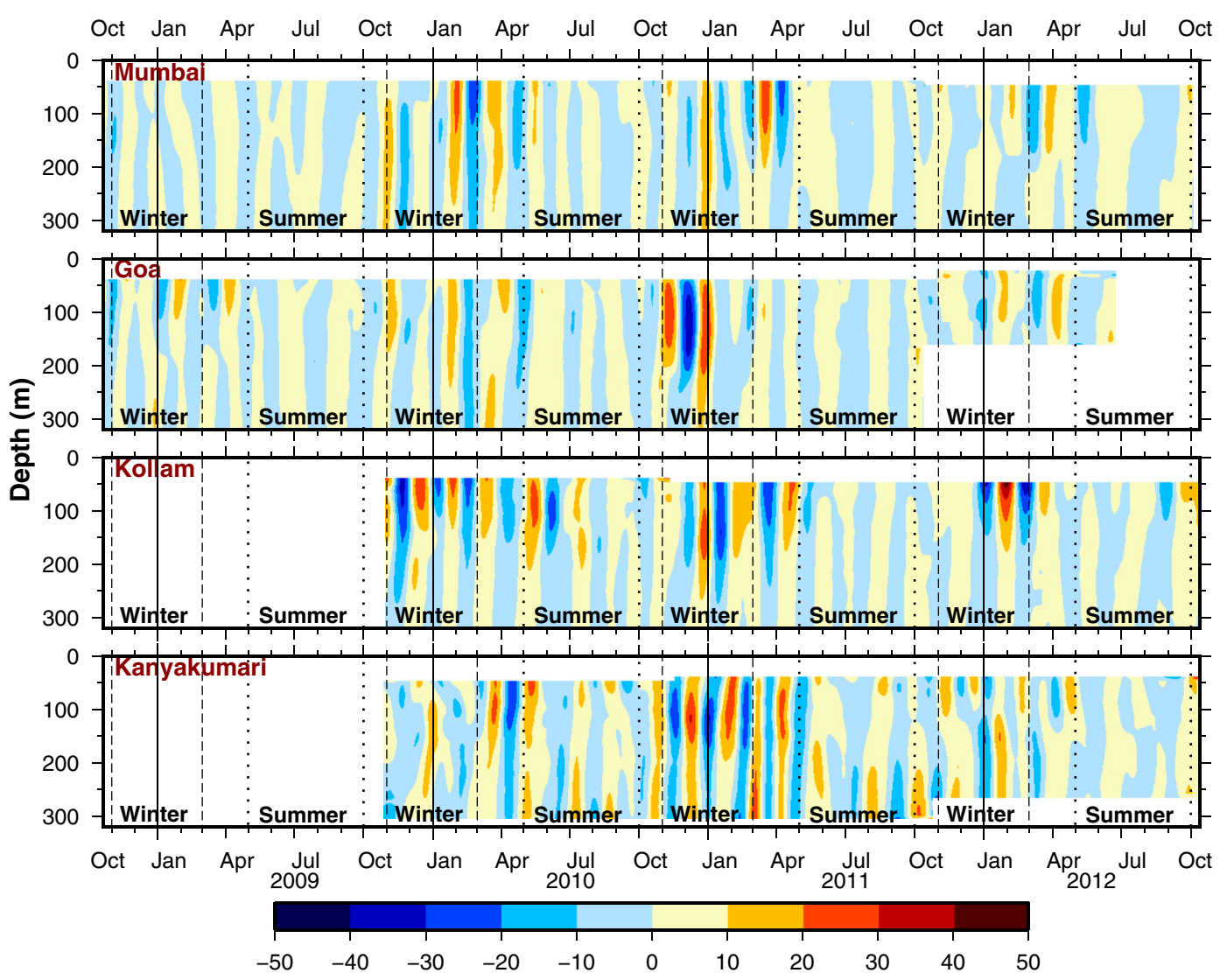

Figure 9. 30-90-day band-passed alongshore currents $\left(\mathrm{cm} \mathrm{s}^{-1}\right)$.

towards Mumbai; in the south, at Kanyakumari, this 4-day peak merges with the inertial peak (figure 4).

\subsection{Undercurrents}

Undercurrents are prominent at all locations during both winter and summer monsoons, but are more evident poleward along the west coast owing to the upward phase propagation (figures 2, 7, and 9). An example is the equatorward undercurrent, above which is a strong poleward surface current, during the winter of 2009 at Goa; the upward phase propagation associated with the seasonal cycle (figures 6 and 7 ) leads to this undercurrent. On occasions, the magnitude of the undercurrent is comparable to that of the surface current. This association of undercurrents with upward phase propagation explains the different depths at which undercurrents have been observed to occur. For example, hydrographic data (Shetye et al. 1990, 1991a) suggest that the undercurrent occurs at a depth of 100-250 m, but (Stramma et al. 1996) noted that the poleward undercurrent during August 1993 extended till the top depth bin $(24-32 \mathrm{~m})$ of the shipborne ADCP, while the ship-drift data at the same time showed a weak, equatorward surface flow.

\section{Cross-shore currents}

Though alongshore flows are known to dominate the coastal currents, the ADCP data show that the cross-shore current is comparable at times to the alongshore current. When filtered with a 5-day lowpass Butterworth filter, strong cross-shore currents are seen in the ADCP data at Kanyakumari and Kollam (figure 10). As with the alongshore current, the cross-shore current is strong during the winter monsoon and is dominated by intraseasonal variability, with the current reversing direction several times during November-February. During the summer monsoon, intraseasonal variability is weaker and the cross-shore flow is generally towards the coast. This seasonal difference is seen at all four locations even though the cross-shore current is weaker at Mumbai and Goa. An exception occurs during the winter monsoon of 2011 (November 2011-February 2012) at Kollam: the cross-shore current is directed onshore over most of the season.

A comparison between near-surface alongshore and cross-shore currents (figure 11) shows that they are comparable at Kanyakumari and Kollam, where magnitude of the cross-shore current reaches $60-65 \mathrm{~cm} \mathrm{~s}^{-1}$. At Kanyakumari, the upwelling-favourable (downwelling-favourable) alongshore flow is often accompanied by an offshore 


\section{Cross-shore currents $\left(\mathrm{cm} \mathrm{s}^{-1}\right)$}
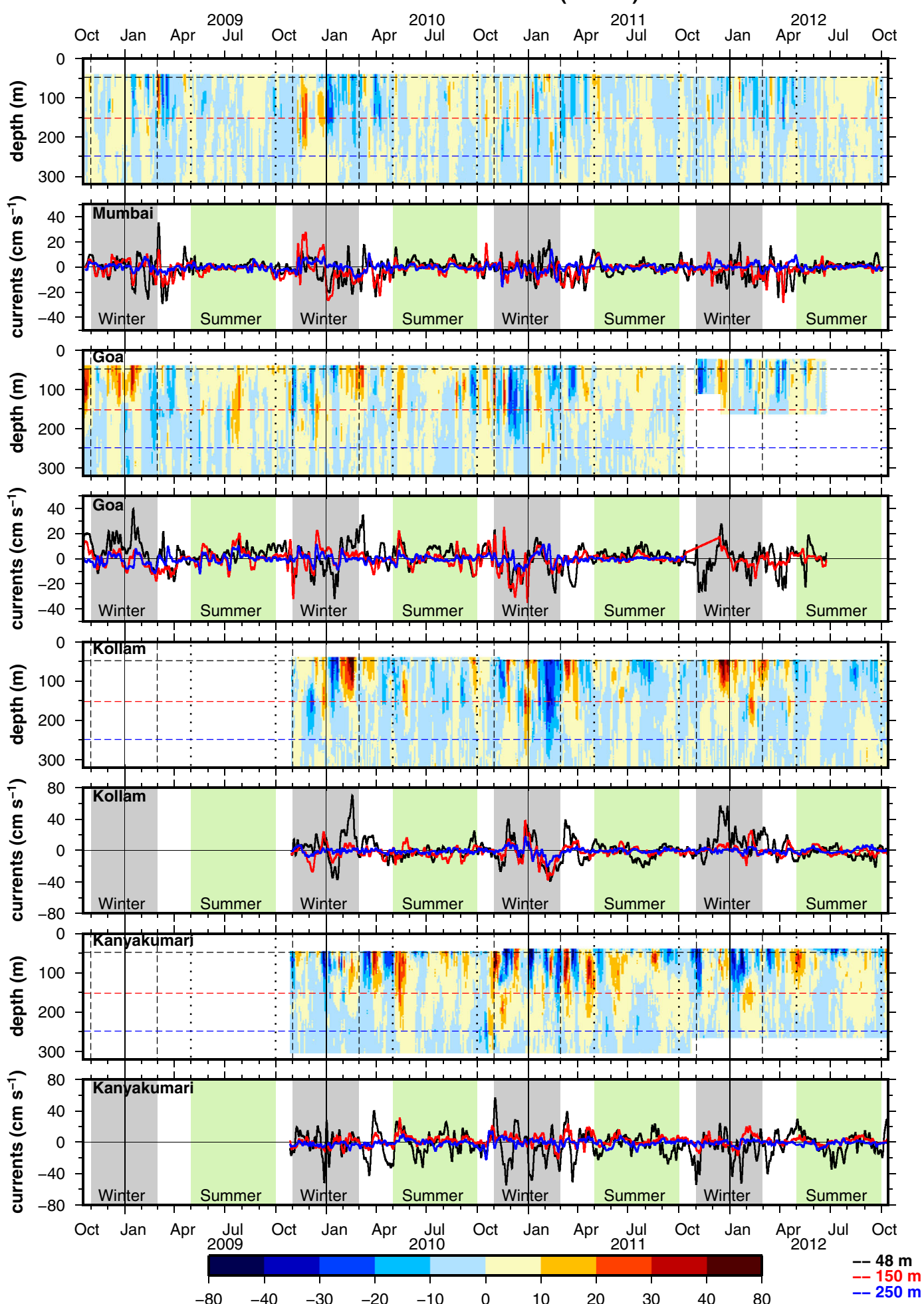

Figure 10. Panels (a), (c), (e), and (g) show the 5-day low-passed cross-shore currents as a function of depth. Blue shade implies westward (equatorward) flow and red shade eastward (poleward) flow at Kollam, Goa and Mumbai (Kanyakumari). The dotted and dashed vertical lines are drawn to delineate summer and winter monsoons, respectively. The dashed horizontal lines mark the $48 \mathrm{~m}$ (black), $150 \mathrm{~m}$ (red), and $250 \mathrm{~m}$ (blue) water depth. Panels (b), (c), (f), and (h) show corresponding line plots for currents at $48 \mathrm{~m}$ (black), $150 \mathrm{~m}$ (red), and $250 \mathrm{~m}$ (blue). 


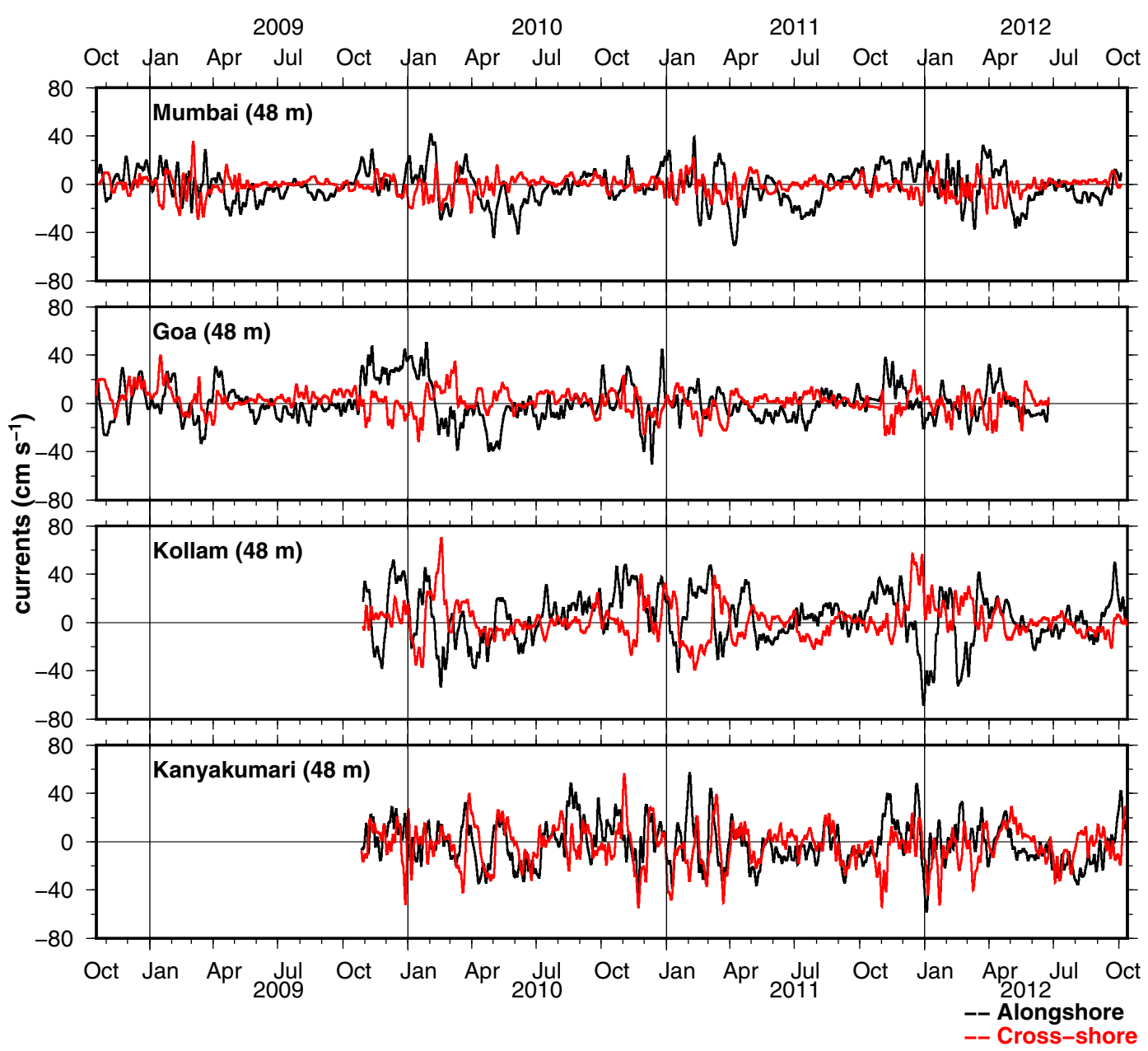

Figure 11. Comparison between alongshore and cross-shore currents at $48 \mathrm{~m}$. When the alongshore flow is positive (negative), the flow is downwelling (upwelling) favourable. Similarly, the positive (negative) sign in the cross-shore flow indicates that the flow is onshore (offshore).

(onshore) drift, but this is not true at the other locations, where a poleward (equatorward) flow is matched by an onshore (offshore) flow only on a few occasions: an example is the equatorward (poleward) and offshore (onshore) flow during December 2010 at Goa (Kollam).

The histogram (figure 3) is almost symmetric and the current at $48 \mathrm{~m}$ is $20 \mathrm{~cm} \mathrm{~s}^{-1}$ over almost $70 \%$ of the record. The Goa currents show a strong onshore drift at $48 \mathrm{~m}$ over about $64 \%$ of the record. At $150 \mathrm{~m}$, the currents are much weaker, exceeding $10 \mathrm{~cm} \mathrm{~s}^{-1}$ over less than $20 \%$ of the record. As with the alongshore current, the depth-averaged mean cross-shore current is weaker than $1 \mathrm{~cm} \mathrm{~s}^{-1}$ at all locations (figure 3); the maximum mean current is $\sim 3 \mathrm{~cm} \mathrm{~s}^{-1}$ offshore near the surface at Kanyakumari. The standard deviation also decreases with depth and poleward along the coast.

Seasonal and intraseasonal variability are evident in the FFT analysis (figure 4). Unlike for the alongshore currents, for which the FFT suggests that the annual cycle is strong at the northern moorings, the FFT suggests that the annual cycle of the cross-shore currents is relatively stronger at Kollam, but weakens at Goa and Mumbai. Though these periodicities are also seen in the subsurface cross-shore flow (figure not shown), the magnitude is weaker. As with the alongshore current (figure 5), a wavelet analysis of the cross-shore current suggests significant interannual variability at these periodicities associated with the seasonal cycle (figure 12). For example, the annual cycle at Kollam is stronger during 2011-2012 and the 150-day variability at Kanyakumari is strong only in 2012.

As with the alongshore current, the FFT analysis shows stronger intraseasonal variability in the 3090-day band for the cross-shore current (figure 4). Like the alongshore currents, the cross-shore currents weaken poleward in the intraseasonal band. At Mumbai, the inertial current is much stronger than the intraseasonal current, which peaks during the winter monsoon (figure 12); a similar seasonal 


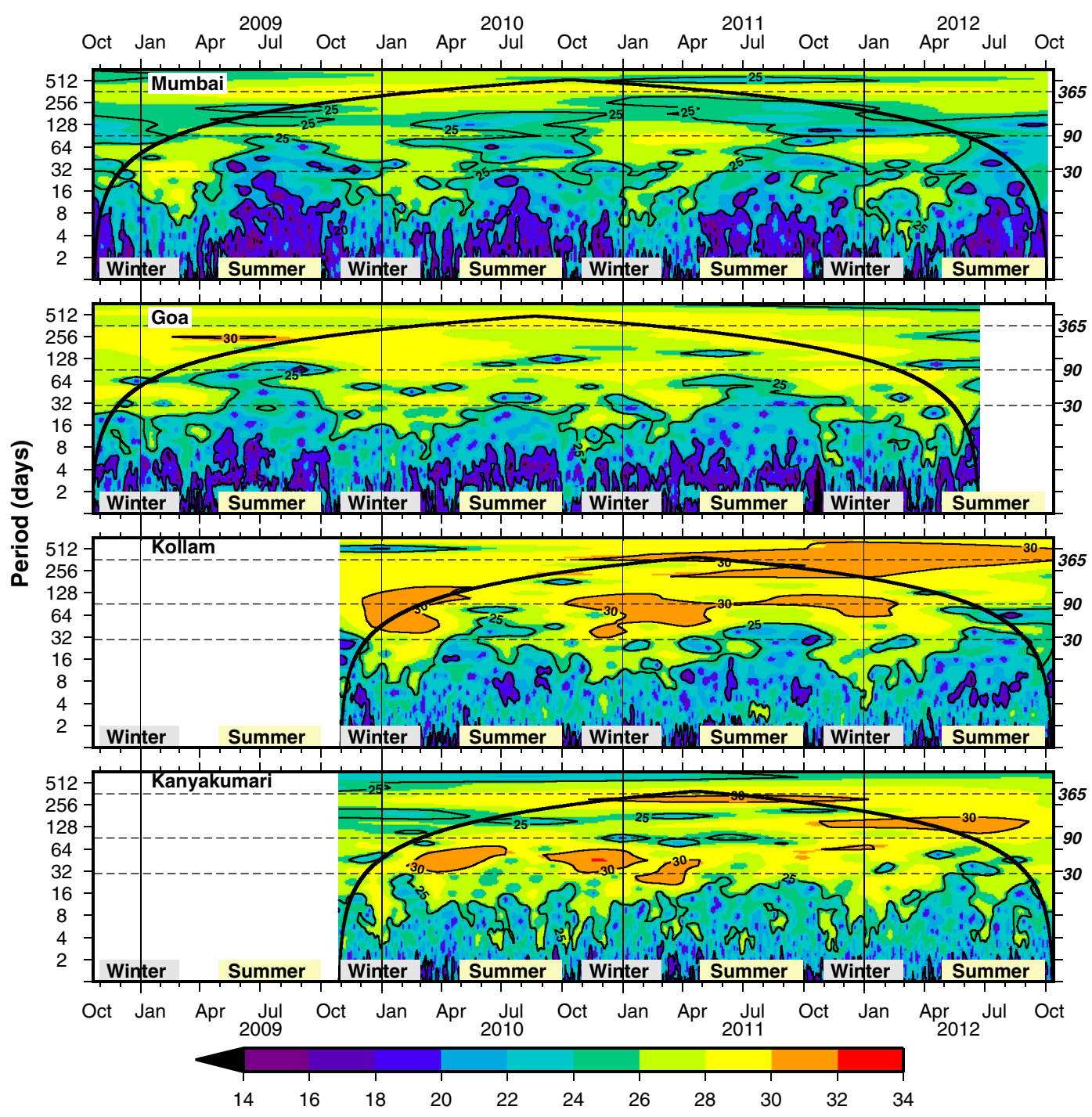

Figure 12. Morlet wavelet power spectra for cross-shore currents at $48 \mathrm{~m}$ depth. The thick black lines show the cone of influence (COI) for the wavelet power spectra. The wavelet power is plotted on a $\log _{2}$ scale. The horizontal dashed lines mark the 30-day, 90-day, and 365-day periods.

difference was noted earlier for the alongshore current (figure 5). Variability at periods shorter than 30 days is also seen and the FFT analysis suggests that this variability weakens poleward (figures 4 and 12).

Unlike the alongshore currents, which show some alongshore coherence (figure 8 ), the crossshore currents are completely decorrelated along the coast with a noticeable phase lag (figure not shown). In-phase coherence is observed only at Kollam and Goa during the winters of 2009-2010 and 2011-2012. At all other times, when coherence is observed, the southern mooring leads the northern mooring by about 10-30 days.

We discuss the reasons for the strong cross-shore flow at Kanyakumari and Kollam and its poleward weakening in section 6 .

\section{Comparison of data products with ADCP}

The 3-year-long ADCP data record off the Indian west coast provides an opportunity to validate current data products that are widely used as a measure of the circulation. In making the comparison with currents derived from OSCAR, ECCO2, and GODAS, we pick the grid cell that is nearest the ADCP mooring and use WCA to quantify the goodness of the data product for the slope off the Indian west coast. At Kollam and Mumbai, the nearest OSCAR grid point is about $0.5^{\circ}-1^{\circ}$ offshore of the mooring location. WCA has two advantages. First, it picks the time and phase when the two time series show maximum correlation. Second, it computes the correlation separately for each frequency band. Therefore, even if the overall 
comparison is poor, WCA shows frequencies which are captured by the data product.

\section{$5.1 O S C A R$}

Comparison of OSCAR and measured currents have been made earlier (Johnson et al. 2007; Sikhakolli et al. 2013) and the current estimates are regularly validated using moored buoys and global drifters (http://www.oscar.noaa.gov/). Johnson et al. (2007) noted that at latitudes poleward of $10^{\circ}$, OSCAR showed fairly good correlation with the in-situ data, but it underestimated the current. Along the equator, the zonal current showed good correlation, but not the meridional current. These studies, however, are mostly restricted to the Pacific Ocean (Johnson et al. 2007), EIO, and central Bay of Bengal (Sikhakolli et al. 2013), leaving the coastal circulation in the NIO unvalidated owing to absence of in-situ data. Furthermore, most of these moorings are concentrated close to the equator and very few global drifters are available in the NIO. In our analysis, we compare the OSCAR currents, which represent the average current over the top $30 \mathrm{~m}$, to ADCP currents at $48 \mathrm{~m}$ depth (the bin closest to the surface).

The 5-day sampling interval of OSCAR currents implies that they should be able to resolve the seasonal (period greater than 100 days) and the low-frequency intraseasonal (30-90 days) bands seen in the ADCP data, and we do see a reasonable match between OSCAR and ADCP currents (figure 13). However, there are several instances when the OSCAR current is even opposite in direction to the observed flow. An example is seen at Kollam during December 2009-May 2010; this discrepancy leads to a low correlation between ADCP and OSCAR currents at Kollam (table 4). The correlation improves at Mumbai and is best at Goa and Kanyakumari. However, for the cross-shore current, the correlation is lowest at Mumbai.

The WCA for ADCP and OSCAR currents shows strong coherence for periods as low as 30 days (figure 14). The annual cycle shows strong coherence at Goa and Mumbai, but is weaker at Kollam and Kanyakumari. This coherence, however, shows a strong phase lag, with the ADCP generally leading: the phase lag at Mumbai (Goa) is 10-60 (10-20) days. The 150-250-day and 100150-day bands show in-phase coherence at Goa during 2009 and 2010, respectively. Except at Mumbai, where intraseasonal variability is weak in the OSCAR currents (figure 13), the intraseasonal periods show several instances of strong coherence. The coherence is high for the 30-90-day band at Kollam, but OSCAR is 90 degrees (8-25 days)

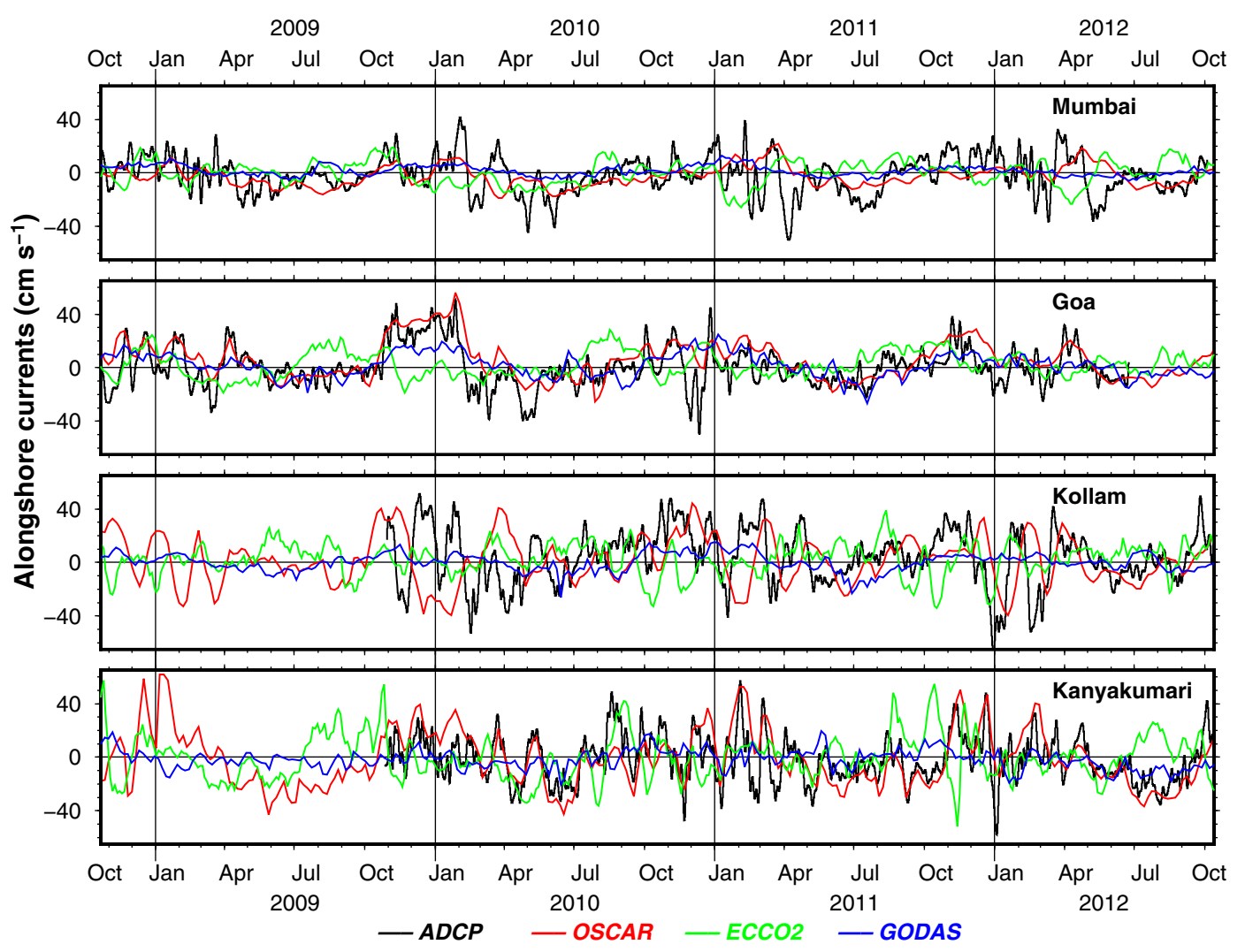

Figure 13. Comparison between alongshore currents $\left(\mathrm{cm} \mathrm{s}^{-1}\right)$ from the ADCPs at $48 \mathrm{~m}$ depth and OSCAR, ECCO2 (50 $\left.\mathrm{m}\right)$, and GODAS $(50 \mathrm{~m})$. 
Table 4. Correlation between currents at $48 \mathrm{~m}$ depth and current-data products (OSCAR, ECCO2, and GODAS) for both alongshore and cross-shore components.

\begin{tabular}{|c|c|c|c|c|c|c|c|c|}
\hline \multirow[b]{2}{*}{ Location } & \multicolumn{4}{|c|}{ Alongshore } & \multicolumn{4}{|c|}{ Cross-shore } \\
\hline & $\overline{\mathrm{KK}}$ & Kollam & Goa & Mumbai & KK & Kollam & Goa & Mumbai \\
\hline OSCAR & 0.60 & 0.00 & 0.67 & 0.25 & 0.53 & 0.53 & 0.46 & -0.09 \\
\hline $\mathrm{ECCO} 2$ & 0.01 & 0.20 & 0.26 & 0.37 & -0.15 & -0.09 & 0.10 & -0.02 \\
\hline GODAS & 0.24 & 0.16 & 0.36 & -0.01 & 0.03 & 0.07 & -0.12 & 0.09 \\
\hline
\end{tabular}

KK: Kanyakumari.

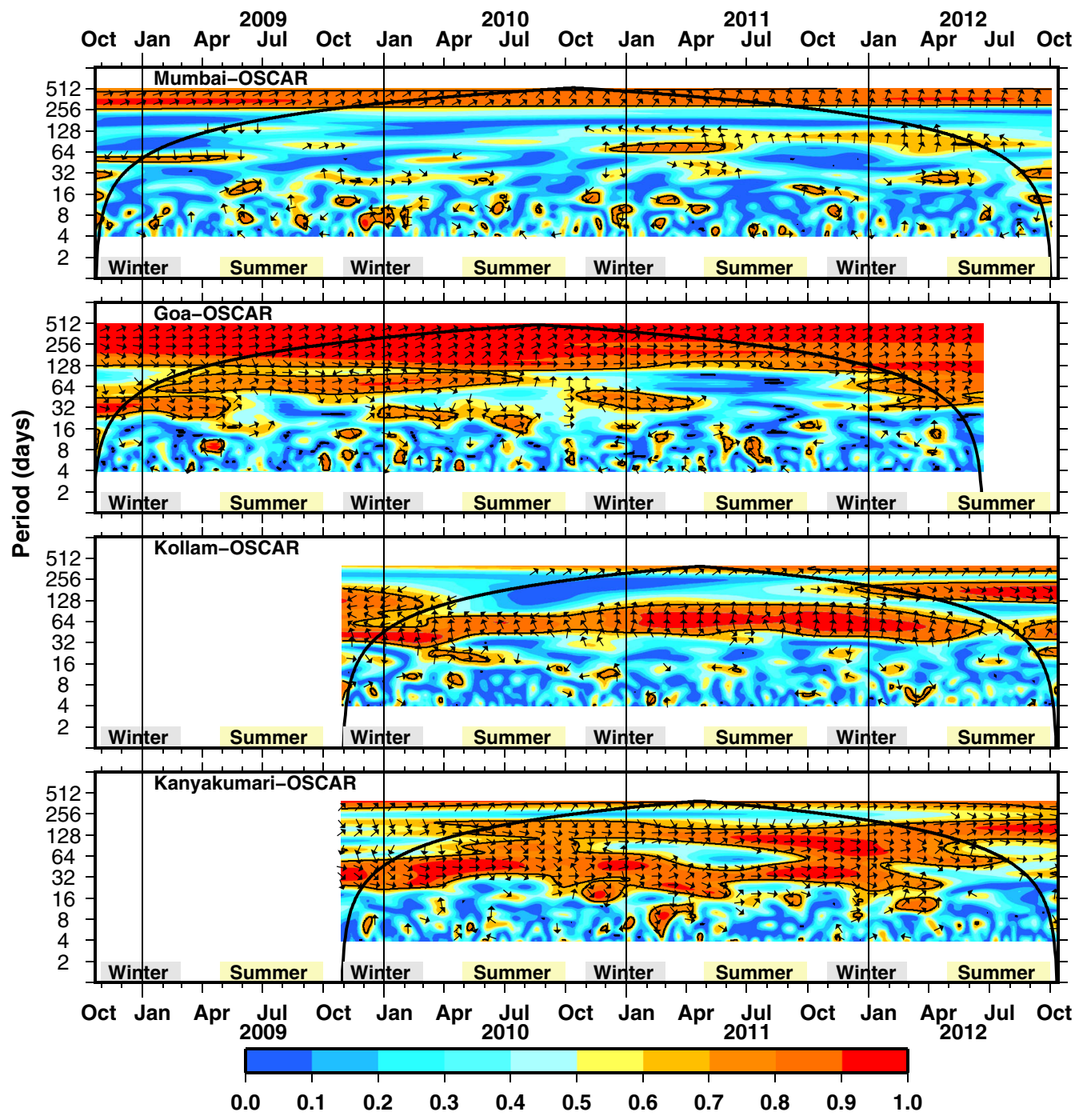

Figure 14. Wavelet coherence between ADCP (at $48 \mathrm{~m}$ ) and OSCAR alongshore currents. The contour line shows $5 \%$ significance level against red noise and the thick black line shows the cone of influence (COI). The arrows show the relative phase relationship with in-phase (anti-phase) pointing right (left). The ADCP current leads (lags) the OSCAR current in anticlockwise (clockwise) direction. Note that the ordinate (period) is plotted on a $\log _{2} \mathrm{scale}$

out of phase, which explains the low correlation observed at this location. An 8-day lag correlation improves the correlation by 0.33 . It is also to be noted that OSCAR, at times, is unable to capture the currents when they are weak, leading to a low coherence. An example is the weak coherence observed during 2010-2011 for the 30-90-day period at Goa. At Kanyakumari, the intraseasonal band is captured reasonably well, with in-phase coherence observed most of the time.

\subsection{ECCO2 and GODAS}

ECCO2 and GODAS have been validated earlier by Pandey and Singh (2010) in the EIO. They 


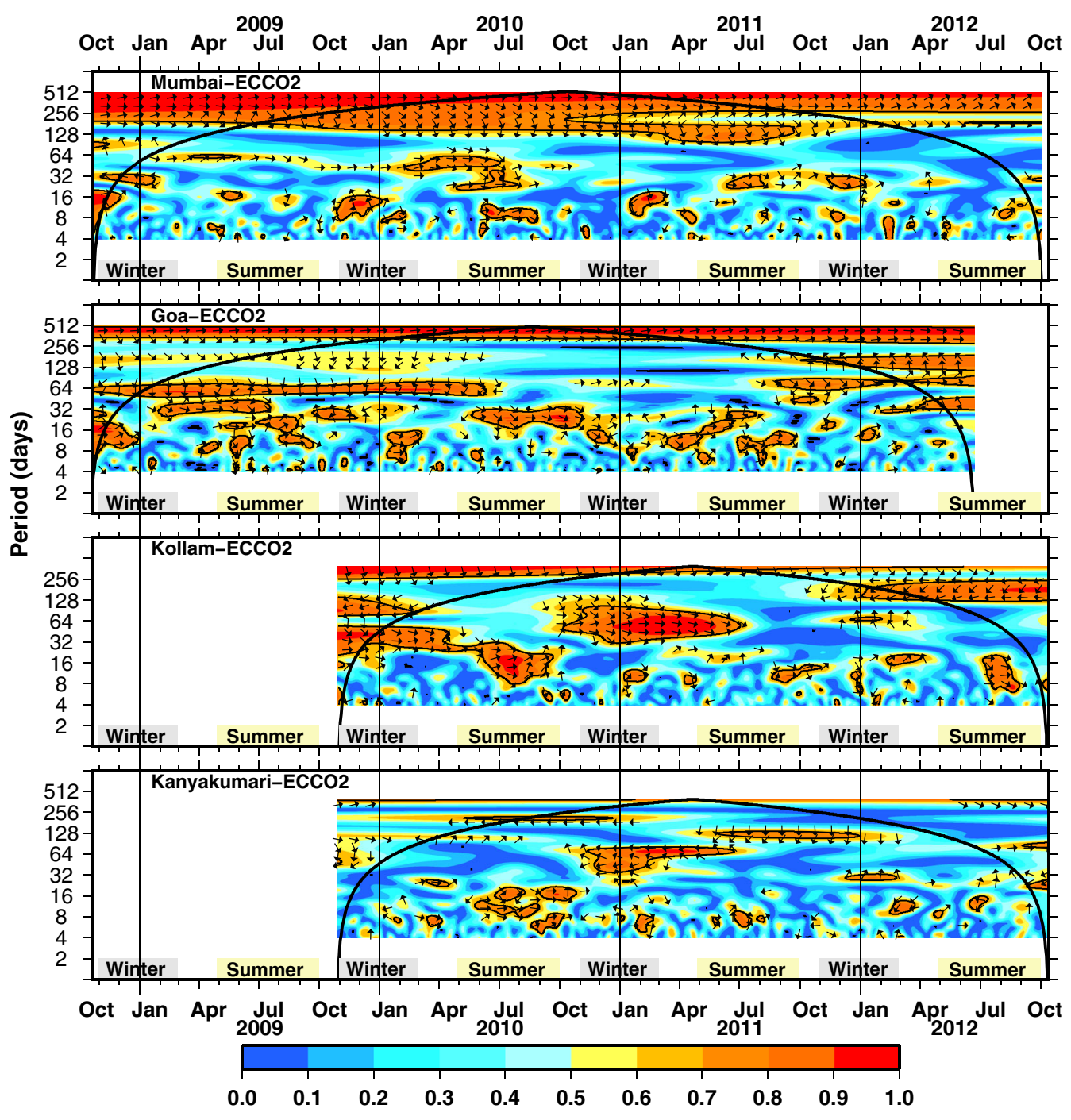

Figure 15. Wavelet coherence between ADCP and ECCO2 model alongshore currents at $48 \mathrm{~m}$ depth. The contour line shows $5 \%$ significance level against red noise and the thick black line shows the cone of influence (COI). The arrows show the relative phase relationship with in-phase (anti-phase) pointing right (left). The ADCP currents leads (lags) the ECCO2 currents in anticlockwise (clockwise) direction. Note that the ordinate (period) is plotted on a $\log _{2}$ scale.

noted a better performance for ECCO2 compared to GODAS. The comparison between ADCP and model data also show a similar result along the west coast of India. Variability is weak at all time scales in GODAS and the model current at $48 \mathrm{~m}$ does not match the ADCP data (figure 13), leading to a low correlation (table 4 ). The WCA shows that even at the seasonal time scale, GODAS is completely out of phase with the observed current (figure not shown).

ECCO2 performs better in that it exhibits more intraseasonal variability for alongshore currents (figure 13). Except at Kanyakumari, the correlation exceeds 0.25 (table 4 ). The WCA shows that ECCO2 captures the seasonal cycle well at Mumbai and Goa (figure 15). In the 30-90-day intraseasonal band, there is a phase difference between ECCO2 and the ADCP, but the variability at Kollam during 2009 and 2010 is in phase. With depth, (a) ECCO2

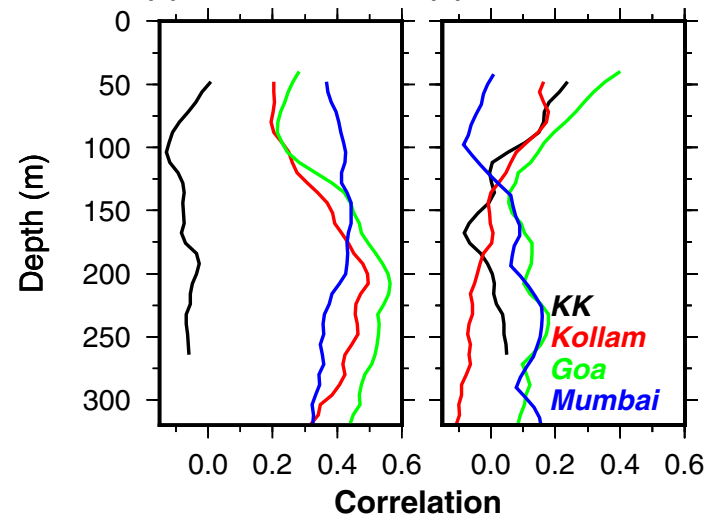

Figure 16. Correlation between alongshore currents from ADCP and (a) ECCO2 (b) GODAS as a function of depth. 


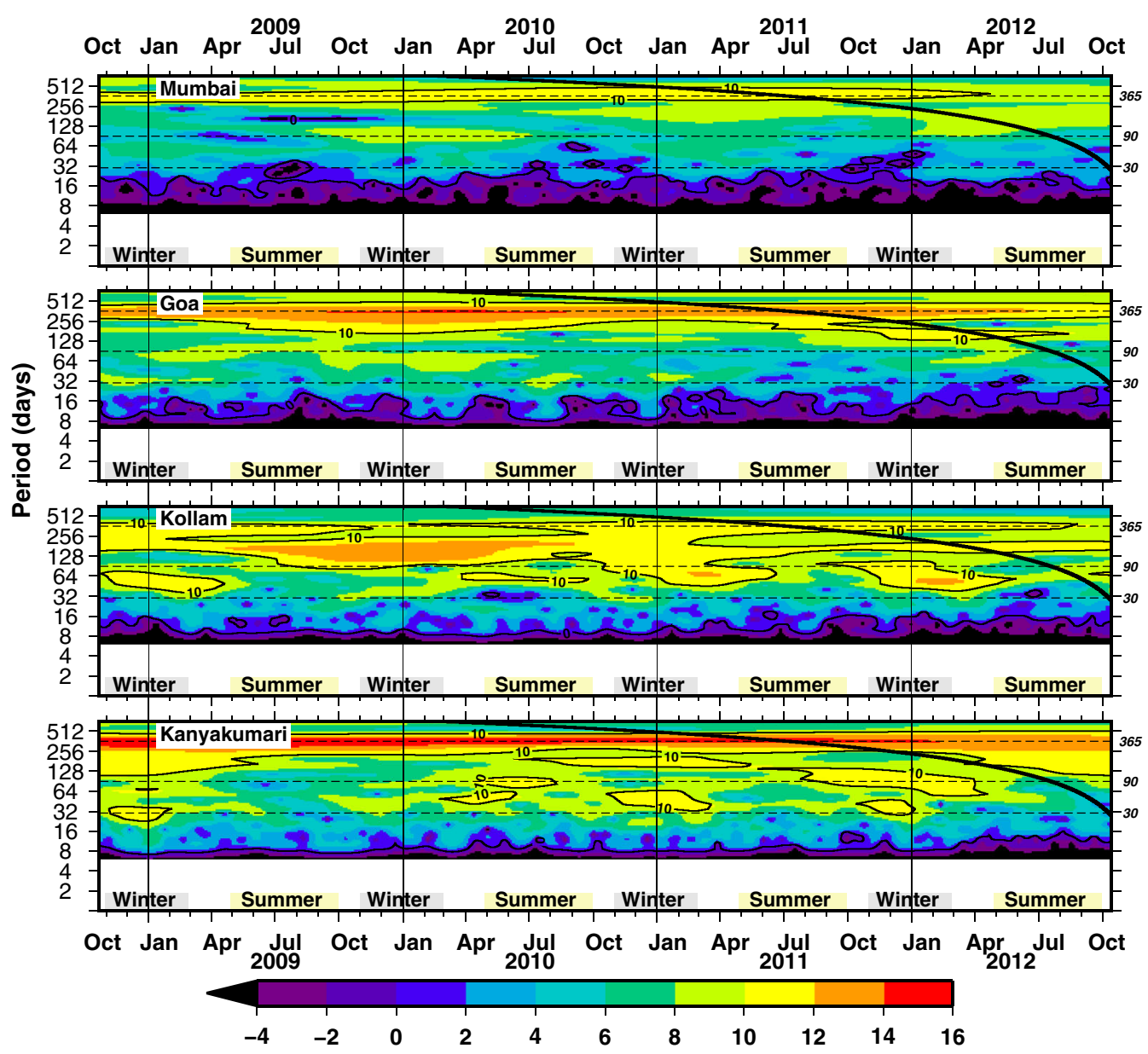

Figure 17. Morlet wavelet power spectra for OSCAR alongshore currents calculated at ADCP locations. The thick black lines show the cone of influence (COI) for the wavelet power spectra. The wavelet power and the ordinate axis is plotted on a $\log _{2}$ scale. The dashed lines mark the 30-day, 90-day, and 365-day periods.

however, the correlation tends to increase at Mumbai (0.44 at $150 \mathrm{~m})$, Goa $(0.56$ at $210 \mathrm{~m})$, and Kollam (0.5 at $210 \mathrm{~m}$ ) (figure 16). The WCA shows that this increase is due to a better simulation of the seasonal cycle in the thermocline.

The correlation is worse for the cross-shore currents.

\section{Discussion}

We have presented data from four ADCPs deployed on the continental slope off the Indian west coast during October 2008-October 2012. The 4-year record length and the sampling interval of $1 \mathrm{hr}$ allow a hitherto unprecedented analysis of the variability of the WICC over a range of frequencies in the top $\sim 300 \mathrm{~m}$ of the water column. (A companion manuscript (Mukherjee et al.) presents a similar analysis for the EICC.) Such an analysis was possible earlier for only the near-surface current with satellite altimeter data, as done for the EICC by Durand et al. (2009), but a comparison with the ADCP data shows that though there are a few similarities (stronger instraseasonal variability in the south, i.e., at Kanyakumari and Kollam), there are significant differences between the ADCP and satellite-derived currents. Both datasets, ADCP and OSCAR, suggest considerable interannual variability of the WICC on the slope, but the seasonal cycle is strong (weak) at Mumbai (Kanyakumari) in the ADCP data (figure 5) and strong (weak) at Kanyakumari and Goa (Kollam and Mumbai) in OSCAR (figure 17). The intraseasonal variability at Mumbai is also much weaker in OSCAR than in the ADCP. We conclude this paper by summarising major features of the WICC as revealed in the ADCP data and discuss possible causes for some of them; a discussion of the causes of all observed features is beyond the scope of this paper and is not possible as even state-of-the-art numerical models fail to simulate the observed currents with reasonable accuracy.

\subsection{The seasonal cycle}

The existence of a strong seasonal cycle at Goa is contrary to the report of Vialard et al. (2009), 
who found the seasonal cycle missing in a shorter ADCP record during 2006-2008. They attributed this absence of the seasonal cycle, which was in contrast to the strong intraseasonal variability in the ADCP current at $50 \mathrm{~m}$ during 2006-2008, to the westward radiation of the seasonal Rossby wave; in contrast, they noted that the critical latitude for radiation of these seasonal Rossby waves was around the latitude of Goa and suggested that coastal trapping at intraseasonal periods less than $\sim 90$ days led to the intraseasonal current. The ADCP data presented here suggest, however, that the annual cycle actually strengthens poleward during 2009-2011 (figure 6), contradicting the hypothesis of Vialard et al. (2009). The data suggest that there is considerable interannual variability even in the seasonal cycle of the WICC (figures 5-7) and there must be some other explanation for its absence during 2006-2008 at Goa. The explanation turns out to be more complex than envisaged and will be the subject of a future paper.

\subsection{Upward phase propagation}

Most striking in the seasonal cycle of the ADCP currents (figures 6 and 7 ) is the upward propagation of phase. The upward phase propagation was also earlier observed in WICC (Amol et al. 2012) and along the southern tip of Sri Lanka (Schott et al. 1994). Since the shallowest common depth for the ADCP data is $48 \mathrm{~m}$ and the climatological mixed-layer depth at the mooring locations (Chatterjee et al. 2012) is shallower than $40 \mathrm{~m}$ (figure 18), it is possible that there can be a lag in phase between the currents analysed in this paper and the surface current. An example is the current at Kanyakumari, where the OSCAR current shows an annual cycle that is absent in the ADCP current. To answer this question, we examined the current data at Goa during November 2011 to June 2012, when the data are available till $24 \mathrm{~m}$ (table 3). The 30-day low-passed current at $24 \mathrm{~m}$ is similar to that at $48 \mathrm{~m}$ (figure 19), but there are occasions (November 2011-February 2012) when

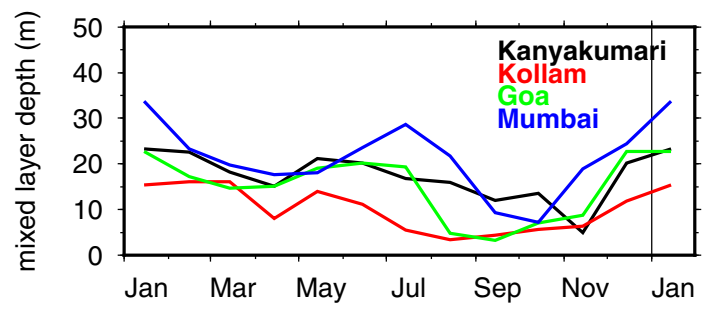

Figure 18. Climatology of mixed layer depth (m) based on Chatterjee et al. (2012) at the ADCP locations. The mixed layer depth is assumed to be the depth at which the density exceeds the surface density by $0.2 \mathrm{~kg} \mathrm{~m}^{-3}$.

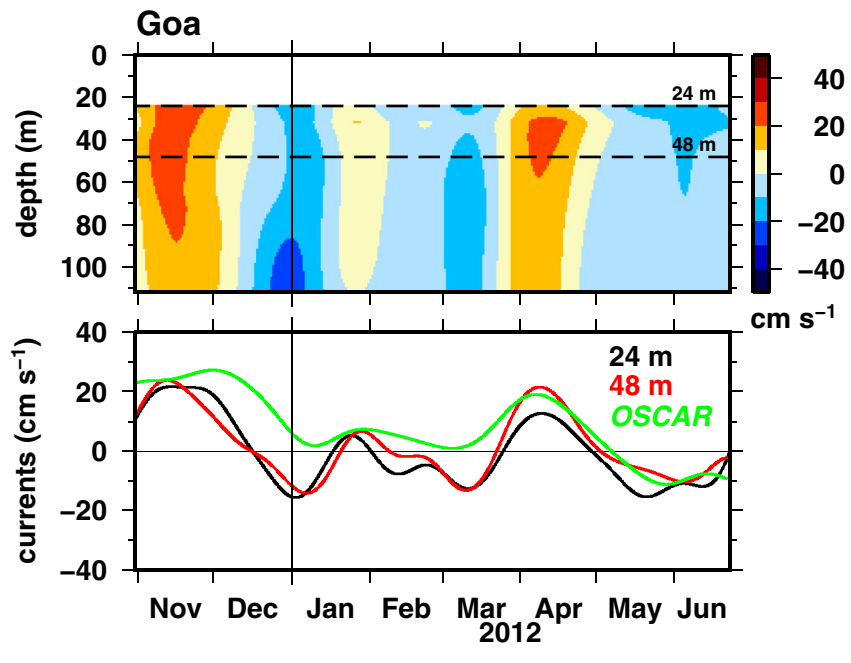

Figure 19. The top panel shows the 30-day low-passed currents as a function of depth at Goa. The bottom panel shows the same 30-day low-pass currents at $24 \mathrm{~m}, 48 \mathrm{~m}$ and for OSCAR.

the former lags the latter owing to upward phase propagation. The OSCAR current lags the $24-\mathrm{m}$ current too, suggesting the possibility that phase propagates upward to even shallower depths. It is possible, but not certain, that the phase difference between the ADCP and OSCAR currents (figure 14) is due to vertical phase propagation. However, note that the currents at $24 \mathrm{~m}$ and $48 \mathrm{~m}$ are in the same direction and the OSCAR current, which represents an average over the top $30 \mathrm{~m}$, is also usually in the same direction, suggesting that the 48-m current represents the surface current over much of the year.

\subsection{Downward phase propagation}

On occasions (April 2012), however, the current at $24 \mathrm{~m}$ leads that at $48 \mathrm{~m}$ and lags the OSCAR current, suggesting downward propagation of phase. Such downward phase propagation is also evident in the ADCP data in the 100-250-day band of the seasonal cycle (figure 7) and in the intraseasonal band (figure 9). Upward propagation of phase is clearly due to downward propagation of energy. Though we cannot determine the reason for the observed downward propagation of phase, it is possible that such patterns are generated by a combination of vertical normal modes associated with locally and remotely forced currents. There even exist occasions, as seen at Kollam during December 2011 to January 2012 in the 100-250-day band (figure 7), when downward phase propagation is observed in the top $\sim 100 \mathrm{~m}$ and upward phase propagation between 100 and $300 \mathrm{~m}$. 


\subsection{Depth of the undercurrent}

The vertical propagation of phase, particularly for the seasonal cycle, leads to an undercurrent (figures 2 and 6 ) that shallows as the season progresses. This link between the undercurrent and vertical phase propagation explains why short-duration observations can lead to differing depths for the undercurrent (Shetye et al. 1991a; Hareeshkumar and Mohankumar 1996; Stramma et al. 1996).

\subsection{Intraseasonal variability}

The magnitude of the intraseasonal current is stronger than that of the seasonal cycle (figure 4). A similar intraseasonal peak in the spectrum at $50 \mathrm{~m}$ during 2006-2008 was attributed by Vialard et al. (2009) to the Madden-Julian Oscillation (MJO) (Madden and Julian 1971, 1972). The ADCP data show that intraseasonal variability is stronger during the winter monsoon (figures 5 and 9), which is consistent with the MJO peak during the boreal winter in the Indian and western Pacific Oceans (Zhang and Dong 2004). Recent modelling studies suggest that equatorial forcing contributes significantly to the intraseasonal sea-level variations along the Indian west coast (Suresh et al. 2013).

\subsection{Alongshore decorrelation}

Except for the seasonal cycle, which is weakly coherent from Kollam to Mumbai, the WICC is mostly decorrelated along the coast (figure 8). This decorrelation is not merely a result of the large inter-mooring spacing, which is about $400-500 \mathrm{~km}$. Such a decorrelation along the west coast was earlier noted for an inter-mooring spacing of even $\sim 200 \mathrm{~km}$ in the intraseasonal band (Amol et al. 2012). One possible reason for the alongshore decorrelation of currents is vertical propagation of energy in the form of coastal beams. Upward propagation of phase implies downward propagation of energy. As shown by McCreary (1984) for the equatorial ocean, several vertical normal modes can combine to form equatorial beams; Nethery and Shankar (2007) applied this idea to the Indian west coast and suggested that energy could propagate downward along the coast in the form of a Kelvin beam. This mechanism was invoked by Amol et al. (2012) to explain the alongshore decorrelation of the alongshore WICC on the slope off the central west coast. Nethery and Shankar (2007) argued that the ray angles would steepen, as at the equator, until the ray reached the ocean bottom (as in their flat-bottomed model). The ray angle $\theta$ is a function of stratification, given by the Brünt-Vaïsala frequency $N_{b}$, and the forcing frequency $\sigma$. Since $\theta=\sigma / N_{b}$, the rays are expected to steepen more, implying greater downward bending of the beam, for higher frequencies and weaker stratification (low $N_{b}$ ). For a typical westcoast density profile off southwest India (Shenoi et al. 2005), Nethery and Shankar (2007) suggested that the beam would bend almost $500 \mathrm{~m}$ for the 30-day period compared to just $\sim 20-30 \mathrm{~m}$ for the annual cycle. Hence, one can expect greater alongshore coherence for the seasonal cycle compared to the intraseasonal component. Restriction of the ADCP data to the top $\sim 350 \mathrm{~m}$ of the water column precludes a statement on whether the vertical phase propagation will occur at greater depths as well. It is, therefore, important to extend the ADCP measurements to the entire water column to map the intraseasonal variability.

\subsection{Cross-shore currents}

The ADCP data at Kollam and Kanyakumari also show fairly strong cross-shore currents (figure 10), which are dominated by intraseasonal variability (figure 4). The magnitude of the cross-shore current is often comparable to the alongshore current at these southern locations. The altimeter data show that there is a considerable match between the offshore flow and decrease in sea level, especially for the seasonal cycle (figure not shown), in which the current generally leads the sea level by 10-30 days. In the intraseasonal band from October 2009 to March 2010, however, the sea level lags the current by about 20-25 days. A careful examination of the altimeter and ADCP data shows that the strong cross-shore flows are invariably associated with eddy-like circulations (see the examples in figure 20). Such eddy-like circulations, embedded within the westward propagating Rossby off southwest India, have been noted earlier too (Bruce et al. 1998; Hareeshkumar et al. 2009; Rao et al. 2013). Note that such eddy-like circulations need not necessarily be nonlinear phenomena: at intraseasonal periods of the order of 60 days, the wavelength is short enough to produce such smallscale 'eddies' (Shankar and Shetye 1997). Such eddy-like circulations are not as strong at Goa and Mumbai owing to the decrease in the characteristic length scale, the Rossby radius, with increasing distance from the equator. This decrease in the crossshore length scale leads to far weaker cross-shore flows at the two northern moorings.

\subsection{Ocean current data products}

Comparison of the OSCAR data product with the in-situ measurements has been discussed above. 

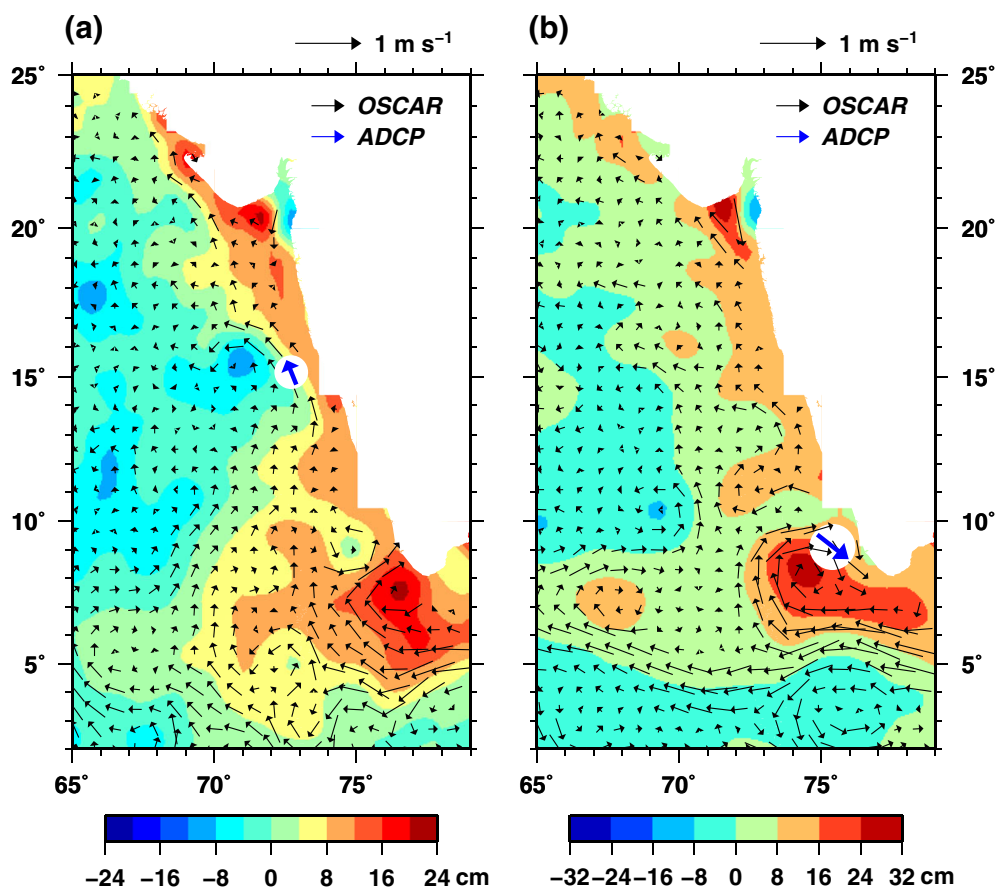

Figure 20. OSCAR currents overlaid over sea-level anomalies (AVISO 1996) for (a) 23 December 2009 and (b) 28 December 2011. The blue arrows show the current vector from the ADCP at Goa and Kollam, respectively.

Unlike with OSCAR, the current in ECCO2, a model-data product, is available at the same depth as the ADCP current, ruling out the possibility of a mismatch owing to vertical phase propagation. The ECCO2 performance is, nevertheless, a function of both space and time (figure 13). Though ECCO2 shows significant seasonal and intraseasonal variability, there is a significant difference in phase with respect to the ADCP (figure 15). GODAS, another model-data product that assimilates observations, fares much worse, showing much less variability than observed in the ADCP currents (figure 13). A possible reason for the poor match, as speculated by Johnson et al. (2007) for OSCAR currents, could be the coarse model resolution. The $1^{\circ}$ longitude resolution of GODAS, in particular, is too coarse to capture the offshore $e$-folding scale of $\sim 114 \mathrm{~km}$ at Kollam (for a characteristic speed of $260 \mathrm{~cm} \mathrm{~s}^{-1}$ associated with even the gravest vertical mode (McCreary et al. 1996)). The Rossby radius decreases with latitude, implying that the resolution of these products is not sufficient for an accurate simulation of boundary currents like the WICC. A poor simulation of the boundary current has serious implications for basin-wide estimates of heat budgets that have been carried out in several studies (Rao et al. 2011, 2012; Chacko et al. 2012; Wu et al. 2012), and it would be of interest to see how well the GODAS model set up at a finer resolution $\left(0.5^{\circ}\right.$, but $0.25^{\circ}$ between $10^{\circ} \mathrm{S}$ and $10^{\circ} \mathrm{N}$ ) as part of the Indian Ocean Forecasting
System (INDOFOS) at the Indian National Centre for Ocean Information Services (INCOIS) (Ravichandran et al. 2013) simulates the observed WICC. The resolution of forcasting system at INCOIS is being improved (Francis et al. 2013) and it will also be interesting to compare the highresolution simulations with the ADCP data.

\subsection{Epilogue}

The ADCP data, particularly the decorrelation of the WICC along the coast and the presence of subsurface current cores, present a modelling challenge similar to that presented by hydrographic observations around 25 years ago (Shetye et al. 1990, 1991a). These hydrographic data, and similar data from the western Bay of Bengal (Shetye et al. 1991b, 1993, 1996), enabled the development of a theoretical framework for the seasonal cycle of circulation in the NIO (see the review by Schott and McCreary 2001); these ADCP data are expected to provide a similar fillip to theoretical studies of intraseasonal variability in the NIO. In conclusion, the ADCP data generated off the Indian west coast reveal facets of the WICC that could not be described before. The observations are continuing and it will be of interest to see if a longer dataset of currents based on ADCP measurements will also show interannual variability associated with the major interannual climatic modes 
of the basin, the El Niño and Southern Oscillation (Philander 1983; Meyers et al. 2007) and the Indian Ocean Dipole (Saji et al. 1999; Webster et al. 1999), or the minima at interannual periods noted in the altimeter data by Shankar et al. (2010).

\section{Acknowledgements}

The state estimates for ECCO2 were provided by the ECCO Consortium for Estimating the Circulation and Climate of the Ocean funded by the National Oceanographic Partnership Program (NOPP); the data were downloaded from http://ecco2.jpl.nasa.gov/products/. The GODAS current data were provided by the NOAA/OAR/ESRL PSD, Boulder, Colorado, USA, from their website at http://www.esrl.noaa. gov/psd/. The OSCAR data were obtained from the Physical Oceanography DAAC of the Jet Propulsion Laboratory (downloaded from http:// www.oscar.noaa.gov/). The altimeter products were produced by Ssalto/Duacs and distributed by AVISO, with support from CNES (http://www. aviso.oceanobs.com/duacs/). The FORTRAN code for wavelet analysis and the $\mathrm{R}$ package for wavelet coherence spectra were downloaded from http://paos.colorado.edu/research/wavelets/ and http://tocsy.agnld.uni-potsdam.de/wavelets/, respectively. All figures in this paper were made using Generic Mapping Tools and the analysis was done using Ferret. Authors also thank the officers, crew, and seamen of CRV Sindhu Sankalp and BTV Sagar Manjusha for providing the necessary support for deploying and recovering the ADCPs. The support from CSIR-NIO's research vessel management group both onshore and offshore is gratefully acknowledged. Financial support for this work was provided by CSIR and INCOIS (Ministry of Earth Sciences). P Amol thanks CSIR for his research fellowship. Finally, the authors acknowledge the critical comments from two anonymous reviewers, which helped them correct mistakes in the FFT analysis and improve the presentation. This is CSIR-NIO contribution 5535.

\section{References}

Amol P, Shankar D, Aparna S G, Shenoi S S C, Fernando V, Shetye S R, Mukherjee A, Agarvadekar Y, Khalap S and Satelkar N P 2012 Observational evidence from direct current measurements for propagation of remotely forced waves on the shelf off the west coast of India; J. Geophys. Res. 117.

Anonymous 1944 Atlas of Surface Currents, Indian Ocean; Technical Report Publication No. 566; U.S. Hydrographic Office; Washington DC.
Anonymous 1952 Indische Oceaan, oceanografische en meteorologische gegevenens; Technical Report Publication No. 135, 2nd edn, 2 vols; Koninklijk Nederlands Meteorologisch Instituut.

Anonymous 1960 Monatskarten für den Indischen Ozean; Technical Report Publikation 2422; Deutsches Hydrographisches Institut; Hamburg.

Antony M K and Shenoi S S C 1993 On the flow, thermal field and winds along the western continental shelf of India; Cont. Shelf Res. 13 425-439.

AVISO 1996 AVISO User Handbook: Merged TOPEX/Poseidon Products; Technical report; Toulouse, France.

Banse K 1959 On upwelling and bottom-trawling off the southwest coast of India; J. Mar. Biol. Assoc. India 1 33-49.

Banse K 1968 Hydrography of the Arabian Sea shelf of India and Pakistan and effects on demersal fishes; Deep Sea Res. 15 45-79.

Behringer D W 2007 The Global Ocean Data Assimilation System (GODAS) at NCEP; In: 11th Symp. on Integrated Observing and Assimilation Systems for Atmosphere, Oceans, and Land Surface; volume 3.3; Amer. Meteor. Soc., San Antonio, TX.

Behringer D W, Ji M and Leetmaa A 1998 An Improved Coupled Model for ENSO prediction and implications for ocean initialization. Part I: The ocean data assimilation system; Mon. Wea. Rev. 126 1013-1021.

Behringer D W and Xue Y 2004 Evaluation of the global ocean data assimilation system at NCEP: The Pacific Ocean; In: Eighth Symposium on Integrated Observing and Assimilation Systems for Atmosphere, Oceans, and Land Surface; volume 2.3; 11-15; Amer. Meteor. Soc., Washington State Convention and Trade Cente, Seattle, Washington.

Bell C, Vassie J and Woodworth P L 1998 POL-PSMSL Tidal Analysis Software Kit 2000 (TASK-2000); Technical report; Proudman Oceanogr. Lab.; Bidston Observatory, Merseyside, UK.

Birol F, Roblou L, Lyard F, Llovel W, Durand F, Renault L, Dewitte B, Morrow R and Mnard Y 2006 Towards using satellite altimetry for the observation of coastal dynamics; In: 15 Years of Progress in Radar Altimetry Symposium; Venice, Italy.

Bonjean F and Lagerloef G S E 2002 Diagnostic model and analysis of the surface currents in the tropical Pacific Ocean; J. Phys. Oceanogr. 32 2938-2954.

Bruce J G, Johnson D R and Kindle J C 1994 Evidence for eddy formation in the eastern Arabian Sea during the northeast monsoon; J. Geophys. Res. 99 7651-7664.

Bruce J G, Kindle J C, Kantha L H, Kerling J L and Bailey J F 1998 Recent observations and modeling in the Arabian Sea Laccadive High region; J. Geophys. Res. 103 7593-7600.

Chacko N, Ravichandran M, Rao R R and Shenoi S S C 2012 An anomalous cooling event observed in the Bay of Bengal during June 2009; Ocean Dynam. 62 671-681.

Chatterjee A, Shankar D, Shenoi S S C, Reddy G V, Ravichandran M, Gopalkrishna V V, Rao E P R, Bhaskar T V S U and Sanjeevan V N 2012 A new atlas of temperature and salinity for the North Indian Ocean; J. Earth Syst. Sci. 121 559-593.

Cutler A N and Swallow J C 1984 Surface currents of the Indian Ocean (to $25^{\circ} \mathrm{S}, 100^{\circ} \mathrm{E}$ ): Compiled from historical data archived by the Meteorological Office, Bracknell, UK; Technical Report Report No. 187; Institute of Oceanographic Sciences; Wormley.

Derber J and Rosati A 1989 A global oceanic data assimilation system; J. Phys. Oceanogr. 19 1333-1347. 
Dileepkumar M 2006 Biogeochemistry of the North Indian Ocean; IGBP-WCRP-SCOPE Rep. Ser. 1; Indian Natl. Sci. Acad., New Delhi, India.

Dineshkumar P K and Srinivas K 2007 Variability in measured current structure on the southwest continental shelf of India; J. Coastal Res. 23 647-657.

Düing W 1970 The monsoon regime of the currents in the Indian Ocean; East-West Center Press.

Durand F, Shankar D, Birol F and Shenoi S S C 2008 Estimating boundary currents from satellite altimetry: A case study for the east coast of India; J. Oceanogr. 64 831-845.

Durand F, Shankar D, Birol F and Shenoi S S C 2009 Spatiotemporal structure of the East India Coastal Current from satellite altimetry; Geophys. Res. Lett. 114.

Findlater J 1969 A major low-level air current near the Indian Ocean during the northern summer; Quart. J. Roy. Meteorol. Soc. 95 362-380.

Francis P A, Vinayachandran P N and Shenoi S S C 2013 The Indian ocean forecast system; Curr. Sci. 104 13541368.

Gouveia A D and Varadachari V V R 1979 Coastal and nearshore circulation off Mangalore; Mahasagar 12 175182.

Han W, McCreary J P, Anderson D L T and Mariano A J 1999 Dynamics of the eastern surface jets in the equatorial Indian Ocean; J. Phys. Oceanogr. 29 2191-2209.

Han W, McCreary J P and Kohler K E 2001 Influence of precipitation minus evaporation and Bay of Bengal rivers on dynamics, thermodynamics, and mixed layer physics in the upper Indian Ocean; J. Geophys. Res. 106 68956916.

Hareeshkumar P V, Joshi M, Sanilkumar K V, Rao A D, Anand P, Anilkumar K and Rao C V K P 2009 Growth and decay of the Arabian Sea mini warm pool during May 2000: Observations and simulations; Deep Sea Res. $56528-540$.

Hareeshkumar P V and Mohankumar N 1996 On the flow and thermohaline structure off Cochin during premonsoon season; Cont. Shelf Res. 16 457-468.

Hastenrath S and Greischar L 1989 Climatic Atlas of the Indian Ocean. 3: Upper-Ocean Structure; Technical report; University of Wisconsin Press.

Hurlburt H E, Kindle J C and O'Brien J J 1976 A numerical simulation of the onset of El Niño; J. Phys. Oceanogr. 6 621-631.

Jensen T G 1993 Equatorial variability and resonance in a wind-driven Indian Ocean model; J. Geophys. Res. 98 $22,533-22,552$.

Jensen T G 2001 Arabian Sea and Bay of Bengal exchange of salt and tracers in an ocean model; Geophys. Res. Lett. 28 3967-3970.

Johannessen O M, Subbaraju G and Blindheim J 1987 Seasonal variations of the oceanographic conditions off the southwest coast of India during 1971-1975; FiskDir. Skr. Ser. HavUnders 18 247-261.

Johnson E S, Bonjean F, Lagerloef G S E, Gunn J T and Mitchum G T 2007 Validation and error analysis of OSCAR sea surface currents; J. Atmos. Ocean Tech. 24 688-701.

Kurup P G, Joseph P S and Varadachari V R 1976 Nearshore circulation in the sea off Velsao, Goa; Mahasagar 9 7-10.

Kutsuwada K and McPhaden M 2002 Intraseasonal variations in the upper equatorial Pacific Ocean prior to and during the 1997-98 El Niño; J. Phys. Oceanogr. 32 1133-1149.

Lévy M, Shankar D, André J M, Shenoi S S C, Durand F and Boyer-Montégut C D 2007 Basin-wide seasonal evolution of the Indian Ocean's phytoplankton blooms; J. Geophys. Res. 112.
Longhurst A R and Wooster W S 1990 Abundance of oil sardine (Sardinella longiceps) and upwelling on the southwest coast of India; Can. J. Fish. Aquat. Sci. 47 2407-2419.

Madden R A and Julian P R 1971 Detection of a 40-50 day oscillation in the zonal wind in the tropical Pacific; J. Atmos. Sci. 28 702-708.

Madden R A and Julian P R 1972 Description of global-scale circulation cells in the tropics with a 40-50 day period; J. Atmos. Sci. 29 1109-1123.

Madhupratap M, Nair K N V, Haridas T C G P, Nair K K C, Venugopal P and Gauns M 2001 Arabian Sea oceanography and fisheries of the west coast of India; Curr. Sci. 81 $355-361$.

Mariano A J, Ryan E H, Perkins B D and Smithers S 1995 The Mariano Global Surface Velocity Analysis 1.0; USCG Report CG-D-34-95; Office of Engineering, Logistics, and Development, U.S. Coast Guard.

Marshall J, Adcroft A, Hill C, Perelman L and Heisey C 1997 A finite-volume, incompressible Navier Stokes model for studies of the ocean on parallel computers; J. Geophys. Res. 102 5753-5766.

Masumoto Y, Hase H, Kuroda Y, Matsuura H and Takeuchi K 2005 Intraseasonal variability in the upper layer currents observed in the eastern equatorial Indian Ocean; Geophys. Res. Lett. 32.

Mathew B, Sanilkumar K V, Hareeshkumar P V, Madhusoodanan P and James V V 1991 Thermohaline and current structure off Cochin during December 1986; Indian J. Mar. Sci. 20 244-248.

McCreary J P 1976 Eastern tropical ocean response to changing wind systems with application to El Niño; $J$. Phys. Oceanogr. 6 632-645.

McCreary J P 1984 Equatorial beams; J. Mar. Res. 42 395-430.

McCreary J P, Han W, Shankar D and Shetye S R 1996 Dynamics of the East India Coastal Current: 2. Numerical solutions; J. Geophys. Res. 101 13,993-14,010.

McCreary J P, Kundu P K and Molinari R L 1993 A numerical investigation of the dynamics, thermodynamics and mixed-layer processes in the Indian Ocean; Prog. Oceanogr. 31 181-244.

McCreary J P, Murtugudde R, Vialard J, Vinayachandran P N, Wiggert J D, Shankar R R H D and Shetye S 2009 Biophysical processes in the Indian Ocean; Geoph. Monog. Series 185 9-32.

McCreary J P, Picaut J and Moore D W 1984 Effects of remote annual forcing in the eastern tropical Atlantic Ocean; J. Mar. Res. 42 45-81.

McPhaden M J, Meyers G, Ando K, Masumoto Y, Murty V S N, Ravichandran M, Syamsudin F, Vialard J, Yu L and Yu W 2009 RAMA: The Research Moored Array for African-Asian-Australian Monsoon Analysis and Prediction; Bull. Am. Meteorol. Soc. 90 459480.

Menemenlis D, Hill C, Adcroft A, Campin J M, Cheng B, Ciotti B, Fukumori I, Koehl A, Heimbach P, Henze C, Lee T, Stammer D, Taft J and Zhang J 2005 NASA supercomputer improves prospects for ocean climate research; EOS Trans. AGU $\mathbf{8 6} 86-89$.

Meyers G, McIntosh P, Pigot L and Pook M 2007 The years of El Niño, La Niña, and interactions with the tropical Indian Ocean; J. Climate 20 2872-2880.

Moore D W 1968 Planetary-gravity waves in an equatorial ocean; Ph.D. thesis; Harvard Univeristy.

Mukherjee A, Shankar D, Fernando V, Amol P, Aparna S G, Fernandes R, Michael G S, Khalap S T, Satelkar N P, Agarvadekar Y, Gaonkar M G, Tari A P, Kankonkar $\mathrm{A}$ and Vernekar S Observed seasonal and intraseasonal 
variability of currents along east coast of India; under review.

Muraleedharan P M, RameshKumar M R and Rao L V G 1995 A note on poleward undercurrent along the southwest coast of India; Cont. Shelf Res. 15 165-184.

Nair K V K and Bhattathiri P M A 1968 A note on current measurements at Angria Bank in the Arabian Sea; Bull. Nat. Inst. Sci. 38 289-293.

Nair K V K, Neralla V R and Ganguly A K 1968 Current measurements off Mormugao; Bull. Nat. Inst. Sci. 38 256-262.

Naqvi S W A, Jayakumar D A, Narvekar P V, Naik H, Sarma V V S S, D'Souza W, Joseph S and George M D 2000 Increased marine production of $\mathrm{N}_{2} \mathrm{O}$ due to intensifying anoxia on the Indian continental shelf; Nature $\mathbf{4 0 8}$ 346-349.

Naqvi S W A, Narvekar P V and Desa E 2006 Coastal biogeochemical processes in the North Indian Ocean (14, S-W); The Sea 14 723-780.

Nethery D and Shankar D 2007 Vertical propagation of baroclinic Kelvin waves along the west coast of India; J. Earth Syst. Sci 4 311-339.

O'Brien J J, Adamec D and Moore D W 1978 A simple model of upwelling in the Gulf of Guinea; Geophys. Res. Lett. 5 641-644.

Pacanowski R C and Griffies S M 1998 MOM 3.0 Manual; NOAA/Geophysical Fluid Dynamics Laboratory; Princeton, USA.

Pandey V K and Singh S K 2010 Comparison of ECCO2 and NCEP reanalysis using TRITON and RAMA data at the Indian Ocean Mooring Buoy point; Earth Sci. India 3 226-241.

Philander S G H 1983 El Niño southern oscillation phenomena; Nature 302 295-301.

Picaut J 1983 Propagation of seasonal coastal upwelling in the eastern equatorial Atlantic; J. Phys. Oceanogr. 13 18-37.

Pillai V K, Abidi S A H, Ravindran V, Balachandran K K and Agadi V V 1996 Proceedings of the second workshop on scientific results of FORV Sagar Sampada; Department of Ocean Development, New Delhi.

Potemra J T, Luther M E and O'Brien J J 1991 The seasonal circulation of the upper ocean in the Bay of Bengal; J. Geophys. Res 96 12,667-12,683.

Raghukumar S and Anil A C 2003 Marine biodiversity and ecosystem functioning: A perspective; Curr. Sci. 84 $884-892$.

Ramamirtham C P 1966 On the relative (geostrophic) currents in the south eastern Arabian Sea; J. Mar. Biol. Assoc. India 8 236-243.

Rao S A, Dhakate A R, Saha S K, Mahapatra S, Chaudhari H S, Pokhrel S and Sahu S K 2012 Why is Indian Ocean warming consistently? Climatic Change 110 709-719.

Rao R R, Kumar S S, Ravichandran M and Kumar M S G 2009 Atlas of the Tropical Indian Ocean from satellite observations; Vol. 3. Sea surface height anomaly and nearsurface circulation; Technical report; Indian National Centre for Ocean Information Services (INCOIS); Hyderabad, India.

Rao R R, Molinari R L and Festa J F 1989 Evolution of the climatological near-surface thermal structure of the tropical Indian Ocean: 1. Description of mean monthly mixed layer depth, and sea surface temperature, surface current, and surface meteorological fields; J. Geophys. Res. 94 10,801-10,815.

Rao A R, Rao G N, Sreenivas P and Hareeshkumar P V 2013 Role of meso-scale eddies on circulation in the south eastern Arabian Sea in 2009; Mar. Geod. 36 319-333.
Rao S A, Saha S K, Pokhrel S, Sundar D, Dhakate A R, Mahapatra S, Ali S, Chaudhari H S, Shreeram P, Vasimalla S, Srikanth A S and Suresh R R V 2011 Modulation of SST, SSS over northern Bay of Bengal on ISO time scale; J. Geophys. Res. 116.

Ratnam J V, Giorgi F, Kaginalkar A and Cozzini S 2009 Simulation of the Indian monsoon using the RegCM3ROMS regional coupled model; Clim. Dynam. 33 119139.

Ravichandran M, Behringer D, Sivareddy S, Girishkumar M S, Chacko N and Harikumar R 2013 Evaluation of the global ocean data assimilation system at INCOIS: The Tropical Indian Ocean; Ocean Model 69 123-135.

Saji N H, Goswami B N, Vinayachandran P N and Yamagata $\mathrm{T} 1999$ A dipole mode in the tropical Indian Ocean; Nature 401 360-363.

Sanil Kumar V, Dora G U, Philip C S, Pednekar P S and Jai Singh 2012 Nearshore currents along the Karnataka coast, west coast of India; Int. J. Ocean Clim. Syst. 3 71-84.

Sastry A A R and Myrland P 1959 Distribution of temperature salinity and density in the Arabian Sea along the south Malabar coast (south India) during the postmonsoon season; Indian J. Fish. 6 223-255.

Schott F A and McCreary J P 2001 The monsoon circulation of the Indian Ocean; Prog. Oceanogr. 51 1-120.

Schott F, Reppin J and Fischer J 1994 Currents and transports of the monsoon current south of Sri Lanka; J. Geophys. Res. 99 25,127-25,141.

Schott F A, Xie S P and McCreary J P 2009 Indian Ocean circulation and climate variability; Rev. Geophys. 47.

Sengupta D, Senan R, Murty V S N and Fernando V 2004 A biweekly in the equatorial Indian Ocean; J. Geophys. Res. 109.

Shankar D, Aparna S G, McCreary J P, Suresh I, Neetu S, Durand F, Shenoi S S C and Saafani M A A 2010 Minima of interannual sea-level variability in the Indian Ocean; Prog. Oceanogr. 84 225-241.

Shankar D, McCreary J P, Han W and Shetye S R 1996 Dynamics of the East India Coastal Current: 1. Analytic solutions forced by interior Ekman pumping and local alongshore winds; J. Geophys. Res. 101 13,975-13,991.

Shankar D and Shetye S R 1997 On the dynamics of the Lakshadweep high and low in southeastern Arabian Sea; J. Geophys. Res. 102 12,551-12,562.

Shankar D, Vinayachandran P N and Unnikrishnan A S 2002 The monsoon currents in the North Indian Ocean; Prog. Oceanogr. 52 63-120.

Sharma G S 1968 Seasonal variation of some hydrographic properties of the shelf waters off the west coast of India; Bull. Nat. Inst. Sci. India 38 263-276.

Shenoi S S C and Antony M K 1991 Current measurements over the western continental shelf of India; Cont. Shelf Res. 11 81-93.

Shenoi S S C, Antony M K and Sundar D 1988 Nature of the observed oscillatory flows in shelf waters of the western continental shelf of India; J. Coastal Res. 4 617-626.

Shenoi S S C, Saji P and Almeida A 1999 Near-surface circulation and kinetic energy in the tropical Indian Ocean derived from Lagrangian drifters; J. Mar. Res. 57 885-907.

Shenoi S S C, Shankar D, Michael G S, Kurian J, Varma K K, Kumar M R R, Almeida A M, Unnikrishnan A S, Fernandes W, Barreto N, Gnanaseelan C, Mathew R, Praju K V and Mahale V 2005 Hydrography and water masses in the southeastern Arabian Sea during March-June 2003; J. Earth Syst. Sci. 5 475-491.

Shenoi S S C, Shankar D and Shetye S R 2002 Differences in heat budgets of the near-surface Arabian Sea and 
Bay of Bengal: Implications for the summer monsoon; J. Geophys. Res. 107 5-1-5-14.

Shetye S R and Gouveia A D 1998 Coastal circulation in the North Indian Ocean: Coastal segment (14, S-W); The Sea $11523-556$.

Shetye S R and Shenoi S S C 1988 Seasonal cycle of surface circulation in the coastal North Indian Ocean; Proc. Indian Acad. Sci. (Earth Planet Sci.) 97 53-62.

Shetye S R, Shenoi S S C, Antony M K and Kumar V K 1985 Monthly-mean wind stress along the coast of the North Indian Ocean; Proc. Indian Acad. Sci. (Earth Planet Sci.) 94 129-137.

Shetye S R, Gouveia A D, Shenoi S S C, Sundar D, Michael G S, Almeida A M and Santanam K 1990 Hydrography and circulation off the west coast of India during the southwest monsoon 1987; J. Mar. Res. 48 359-378.

Shetye S R, Gouveia A D, Shenoi S S C, Michael G S, Sundar D, Almeida A M and Santanam K 1991a The coastal current off western India during the northeast monsoon; Deep Sea Res. 38 1517-1529.

Shetye S R, Shenoi S S C, Gouveia A D, Michael G S, Sundar D and Nampoothiri G 1991b Wind-driven coastal upwelling along the western boundary of the Bay of Bengal during the southwest monsoon; Cont. Shelf Res. 11 1397-1408.

Shetye S R, Gouveia A D, Shenoi S S C, Sundar D, Michael G S and Nampoothiri G 1993 The western boundary current of the seasonal subtropical gyre in the Bay of Bengal; J. Geophys. Res. 98 945-954.

Shetye S R, Gouveia A D and Shenoi S S C 1994 Circulation and water masses of the Arabian Sea, biochemistry of the Arabian Sea, present information and gaps; Proc. Indian Acad. Sci. (Earth Planet. Sci.) 103(2) 107-123.

Shetye S R, Gouveia A D, Shankar D, Shenoi S S C, Vinayachandran P N, Sundar D, Michael G S and Nampoothiri G 1996 Hydrography and circulation in the western Bay of Bengal during the northeast monsoon; J. Geophys. Res. 101 14,011-14,025.

Shetye S R, Suresh I, Shankar D, Sundar D, Jayakumar S, Mehra P, Prabhudesai R G and Pednekar P S 2008 Observational evidence for remote forcing of the West India Coastal Current; J. Geophys. Res. 113.

Sikhakolli R, Sharma R, Basu S, Gohil B S, Sarkar A and Prasad K V S R 2013 Evaluation of OSCAR ocean surface current product in the tropical Indian Ocean using in-situ data; J. Earth Syst. Sci 122(1) 187-199.

Sindhu B, Suresh I, Unnikrishnan A S, Bhatkar N V, Neetu and Michael G S 2007 Improved bathymetric datasets for the shallow water regions in the Indian Ocean; J. Earth Syst. Sci. 116 261-274.

Sreenivas P, Chowdary J S and Gnanaseelan C 2012a Impact of tropical cyclones on the intensity and phase propagation of fall Wyrtki jets; Geophys. Res. Lett. 39.

Sreenivas P, Gnanaseelan C and Prasad K V S R 2012b Influence of El Niño and Indian Ocean Dipole on sea level variability in the Bay of Bengal; Global Planet. Change 80-81 215-225.
Stammer D, Wunsch C, Fukumori I and Marshall J 2002a State estimation in modern oceanographic research; EOS Trans. AGU $\mathbf{8 3}$ 289, 294-295.

Stammer D, Wunsch C, Giering R, Eckert C, Heimbach P, Marotzke J, Adcroft A, Hill C N and Marshall J 2002b The global ocean circulation during 1992-1997, estimated from ocean observations and a general circulation model; J. Geophys. Res. 1073118.

Stramma L, Fischer J and Schott F 1996 The flow field off southwest India at $8 \mathrm{~N}$ during the southwest monsoon of August 1993; J. Mar. Res. 54 55-72.

Suresh I, Vialard J, Lengaigne M, Han W, McCreary J, Durand F and Muraleedharan P M 2013 Origins of winddriven intraseasonal sea level variations in the North Indian Ocean coastal waveguide; Geophys. Res. Lett. 40 $5740-5744$.

Swamy G N, Kolhatkar V M and Fernandes A A 1980 Currents and siltation at Dharamtar creek, Bombay; Mahasagar 13 191-203.

Unnikrishnan A S and Antony M K 1990 On vertical velocity fluctuations and internal tides in an upwelling region off the west coast of India; Estuarine Coast. Shelf Sci. 31 $865-873$.

Varadachari V V R and Sharma G S 1967 Circulation of the surface waters in the North Indian Ocean; J. Indian Geophys. Union 4 61-73.

Varkey M J 1980 Power spectra of currents off Bombay; Indian J. Mar. Sci. 9 278-280.

Varkey M J, Premchand K and Sastry J S 1978 Current measurements off Bombay during March 1976; Mahasagar 11 115-123.

Vialard J, Shenoi S S C, McCreary J, Shankar D, Durand F, Fernando V and Shetye S R 2009 Intraseasonal response of the Northern Indian Ocean coastal waveguide to the Madden-Julian Oscillation; Geophys. Res. Lett. 36.

Vinod Kumar K, Aboobacker V M, Saheed P P and Vethamony P 2012 Coastal circulation along the central west coast of India during cyclone Phyan: Measurements and numerical simulations; Nat. Hazards 64 259-271.

Webster P J, Moore A M, Loschnigg J P and Leben R R 1999 Coupled ocean-atmosphere dynamics in the Indian Ocean during 1997-1998; Nature 401 356-360.

Wu G, Guan Y, Liu Y, Yan J and Mao J 2012 Air-sea interaction and formation of the Asian summer monsoon onset vortex over the Bay of Bengal; Clim. Dynam. 38 261-279.

Wyrtki K 1971 Oceanographic atlas of the International Indian Ocean Expedition; Washington DC: National Science Foundation.

Wyrtki K 1973 Physical oceanography of the Indian Ocean: The Biology of the Indian Ocean (ed.) B Zeitzschel, Springer-Verlag, Berlin.

Wyrtki K 1975 El Niño - the dynamic response of the equatorial Pacific ocean to atmospheric forcing; J. Phys. Oceanogr. 5 572-584.

Yu L, O'Brien J J and Yang J 1991 On the remote forcing of the circulation in the Bay of Bengal; J. Geophys. Res. 96 20,449-20,454.

Zhang C and Dong M 2004 Seasonality in the MaddenJulian Oscillation; J. Climate 17 3169-3180. 